\title{
Study on the Compliance Management of the Electricity Market in China Based on the Evolutionary Game Theory
}

\author{
Luosong Jin, ${ }^{1}$ Chang He, ${ }^{1}$ Xiangyang Wang, ${ }^{1}$ Wei Wang, ${ }^{2}$ and Panting Zhao ${ }^{3}$ \\ ${ }^{1}$ Zhejiang Electricity Trading Centre Co., Ltd., Hangzhou, Zhejiang 310009, China \\ ${ }^{2}$ Zhejiang Huayun Mdt Info Tech Ltd., Hangzhou, Zhejiang 310008, China \\ ${ }^{3}$ China Centre for Energy Economics Research, School of Economics, Xiamen University, Xiamen 361005, China \\ Correspondence should be addressed to Panting Zhao; rainbowzpt@163.com
}

Received 20 January 2021; Revised 21 February 2021; Accepted 5 March 2021; Published 13 March 2021

Academic Editor: Shenggang Li

Copyright ( $\odot 2021$ Luosong Jin et al. This is an open access article distributed under the Creative Commons Attribution License, which permits unrestricted use, distribution, and reproduction in any medium, provided the original work is properly cited.

China's new round of power system reform has further released market vitality, making the power market more open and diversified. Meanwhile, China's power market faces various risks and challenges incurred by this new reform, which further highlights the importance of the compliance management. However, the study on effective compliance management of China's power market is missing, and the way to achieving effective compliance management is still unanswered. This paper tries to fill the research gap using the evolutionary game theory. We constructed a tripartite game model to analyze the strategic choices and influencing factors of power generators, compliance departments of the trading centre, and government regulatory agencies. Furthermore, simulation analysis was conducted based on evolutionary stable strategies. The results show that effective compliance management can be achieved without government supervision if the market mechanism is properly designed. In addition, the costs and profits of market participants and regulators are important factors influencing the effectiveness of compliance management. Our findings may arouse inspiration for the policy makers to construct an effective compliance management system.

\section{Introduction}

The power market reform is closely related to the fundamental life quality issue and the economic and social development of Chinese society [1]. China's power industry has undergone two rounds of power system reform since 2002, and an open, diversified, and competitive power market is gradually taking shape. The theme of China's two rounds of power system reform is "controlling the middle and letting go of the two ends." "Controlling the middle" means strengthening government management in the power grid, transmission, and distribution links. "Letting go of the two ends" means strengthening marketization for power generators, retailers, and consumers to promote more adequate competition. In particular, the new round of power system reform in 2015 broke the single mode of power grid "monopoly purchase and sales." Consequently, diversified trading modes with direct trading as the main mode and the coexistence of spot trading, cross-provincial and cross- regional trading, generation rights trading, and carbon emission rights trading are gradually taking shape [2]. Traditional energy generation and greenhouse gas emissions fundamentally lead to global warming and climate change, posing a great threat to the human society [3]. Therefore, the new round of power system reform has made the liberalization on the power generation side more thorough, and the scale of market-oriented transactions has significantly expanded [4]. Moreover, renewable energy power represented by "wind power" and "photovoltaics" has entered the market. With the emergence of new modes and situations as well as the influx of more social capital, we cannot emphasize the importance of strengthening compliance management too much. China urgently needs to establish an electricity market with "laws to follow, regulated entities, fair transactions, and effective supervision."

Compliance management refers to a series of activities such as improving the compliance management mechanism, risk prevention, and response through establishing a 
compliance management system to ensure the compliance of market participants. The implementation of compliance management is affected by the dynamic interactions of multiple participants. Therefore, effective compliance management requires the close cooperation among all market participants as well as relevant government agencies. Meanwhile, in the context of big data, many data-driven methodologies can be used to analyze management issues [5]. The application of big data can also promote compliance management and prevent compliance risks. To cope with challenges brought by the new round of power system reform, the National Development and Reform Commission issued the "Implementation Opinions on the Establishment and Standard Operation of Power Trading Institutions" at the end of 2015. In accordance with the requirements, the Beijing and Guangzhou power trading centres and more than 30 provincial-level power trading centres were established in 2016.

Trading centres have compliance departments which play three roles: "to the interior," "to the market," and "to the regulatory authorities." To the interior, the compliance department is a department that takes compliance management responsibilities and carries out compliance management. To the market, the compliance department is a professional department that conducts inspection and supervision of the behaviors of participants in the electricity market. To the regulatory authorities, the compliance department also undertakes the task of assisting regulatory authorities to strengthen market supervision as well as accepting the supervision from regulatory authorities. Trading centres are subject to the supervision of regulatory authorities such as government departments, third-party professional evaluation agencies introduced by the government, market management committees, other market participants, and public opinions. The compliance department shall actively cooperate with the external regulatory agencies to enforce compliance management of the electricity market, minimizing the risks of the market and ensuring the orderly development of electricity market-oriented transactions. As market operation institutions, power trading centres are responsible for providing standardized, open, and transparent power trading services for market participants according to the regulations and rules approved by governments. Therefore, trading centres play important roles in compliance management of the electricity market and in assisting government departments to maintain the electricity market order. Moreover, to further promote independent and standardized operation of trading centres, the National Development and Reform Commission and the National Energy Administration jointly issued the "Implementation Opinions on Promoting the Independent and Standardized Operation of Power Trading Institutions" in 2020. Under the principle of "multiple checks and balances," this document is aimed at speeding up the pace of joint-stock reform of trading institutions which currently all take the form of the corporate system. Shareholders of trading institutions shall have independent legal person status and may come from different industries and fields. Furthermore, the proportion of shares held by a single shareholder shall not exceed $50 \%$. In the first half of 2020 , the shareholding ratio of power grid enterprises in the two regional trading institutions in Beijing and Guangzhou and provincial (autonomous regions and municipalities) trading institutions all fell below $80 \%$. By the end of 2020 , the shareholding ratio of grid enterprises fell below $50 \%$.

As a complex system, the whole performance of power market is affected by the interaction of market participants. The essence of electricity market compliance management is a game among the power market participants, the compliance department of the trading centre, and the government. The dynamic changes of each participant make the electricity market not always tend to be balanced. The participants' behaviors are under the supervision of the compliance department, and the compliance department of the trading centre is under the supervision of government agencies. Therefore, the implementation of the compliance management of the power market is affected by the joint action of the power market participants, compliance management departments, and government agencies and has the characteristics of diversity, nonlinearity, and dynamics. The behaviors of the three parties determine the implementation of the compliance management. However, to the best of our knowledge, there is a lack of relevant research, especially research studies considering the interaction between the compliance department of the trading centre and the external supervision. This paper tries to fill the gap, and the contributions of this paper are threefold. First and foremost, taking power generators as the typical representatives of power market participants, this paper constructs a tripartite evolutionary game model for power generators, compliance departments of the trading centre, and government regulatory agencies. Moreover, simulation analysis according to strategy choices and interactions among the three parties is conducted to explore effective ways to promote compliance management. Last but not least, we put forward policy recommendations according to our model results to provide guidance for the policy makers.

The remainder is arranged as follows. Section 2 reviews the relevant literature. Section 3 constructs a tripartite evolutionary game model and analyzes the evolutionary stable strategy (ESS). Section 4 is about the simulation analysis on the ESS and the influencing factors. Section 5 summarizes and makes policy recommendations.

\section{Literature Review}

This paper studies the compliance management of the electricity market based on the evolutionary game theory, which is mainly related to two streams of literature: compliance management of the electricity market and the application of the evolutionary game theory to the electricity market. So far, scholars have done few researches on the compliance management of the electricity market.

The construction of the compliance management system is of great significance to the safe and stable operation of the electricity market. However, there are currently few studies focusing on this field. The relevant literature mostly focuses on the risk management, transmission congestion 
management, and demand-side management. Liu and $\mathrm{Wu}$ [6] explored the risk management in the competitive electricity market and proposed a multilevel electricity transaction risk management framework based on the analysis of market trading environment and market risks. Singh and Parida [7] focused on the congestion management of distributed power plants and proposed a distributed generation distribution approach that takes congestion mitigation and voltage safety into account. This approach helps the ISO best eliminate line overloads under normal and occasional conditions. Tang and Yang [8] studied the compliance risk management of transactions in the electricity market under the background of China's new power system reform. They analyzed the existing problems of compliance risk management in China's power market from three aspects and put forward measures to strengthen compliance risk management. Alashery and Qiao [9] compared different methods of risk management to optimal wind power transactions in the electricity market, such as variance method, $\mathrm{VaR}$, and CVaR, and carried out case studies to compare the performance of the stochastic optimization model without risk management and with different risk management methods. Srivastava [10] studied the transmission congestion management of the electricity market in the context of deregulation of the government and comprehensively analyzed the solutions to the line congestion caused by the open transmission network. They believed that the optimization algorithm can alleviate the congestion of the transmission line and discussed the latest developments in the power industry and the challenges faced by congestion management. Hupez et al. [11] studied the cooperative demand-side management of low-voltage power grids. They believed that, by introducing a cooperation mechanism between suppliers, they can make better use of flexibility to achieve global optimality. They proposed a real-time pricing (RTP) scheme based on cost functions at different times and consumption levels to reflect the true energy costs at different times.

Evolutionary game theory is an effective way to analyze the interaction between two or more players. This theory relaxes the assumption of complete rationality and complete information of players and argues that game players have incomplete information and bounded rationality compared with the static game. Evolutionary game theory has been widely used in the electricity market. Gao and Sheng [12] overviewed the application of evolutionary game theory in the electricity market and analyzed the evolution process of power generators' bidding strategies. They thought that government supervision and regulation are indispensable to the electricity market. Menniti et al. [13] simulated the behavior of producers in the electricity market based on evolutionary game theory. They suggested using evolutionary game theory and the concept of near-Nash equilibrium to simulate the electricity market with more than two producers. Huang and Wang [14] analyzed the bidding strategies of power generators in the electricity market based on the evolutionary game theory and showed that evolutionary game replicator dynamic models can help generators quantitatively predict the strategic trends of their competitors, thereby adjusting their own strategies to get the maximum benefit. Wang et al. [15] used the evolutionary game theory to analyze the bidding strategies of power generators in the electricity market with price elastic demand. The simulation results show that the analysis results of the evolutionary game model are different from those of the traditional game model. Fang et al. [16] constructed an evolutionary game model of renewable energy generation and transmission in China's power market and analyzed the necessity and effectiveness of the government to strengthen relevant regulations. In addition, they also analyzed the influence of exogenous variables of the model through simulations. Cheng and $\mathrm{Yu}$ [17] studied the asymptotic stability analysis of the multigroup asymmetric evolutionary game based on Nash equilibrium under typical scenarios of the power market. Zhu et al. [18] studied the impact of China's renewable energy quota system policy on electricity retailers based on the tripartite evolutionary game and verified the validity of the model using system dynamics. Zhao et al. [19] used the evolutionary game model to analyze the strategies of different types of power generators in the power spot market and analyzed the impact of changes in the daily load demand curve on the revenue of power generators through simulation. Apparently, evolutionary game theory is an effective way to analyze the interaction between two or more players. Different from the static game, this theory relaxes the assumption of complete rationality and complete information of players and argues that game players have incomplete information and bounded rationality. So far, evolutionary game theory has been widely used in the electricity market, but the application to compliance management in the power market is absent. Moreover, the essence of electricity market compliance management is a game among the power market participants, the compliance department of the trading centre, and the government. Therefore, we adopt the evolutionary game model to analyze the interactive strategies among different participants in China's power market.

As can be seen from the above literature, there are few related research studies on the compliance management of the electricity market. The focus of previous studies is mainly on the risk management of the power market, grid congestion management, and demand-side management. Moreover, evolutionary game theory has been widely used in the power field, but to the best of our knowledge, there is no research studying the compliance management of the electricity market based on the evolutionary game theory. This article will study the compliance management of the electricity market based on the evolutionary game theory to fill the gap in this research field.

\section{Tripartite Evolutionary Game of Compliance Management in the Electricity Market}

Compliance management of the electricity market requires close cooperation among market participants and the government. Based on the evolutionary game theory, this section constructs a tripartite evolutionary game of power generators, compliance departments of the trading centre, and government regulatory agencies, analyzing the 
evolutionary stable strategies of all parties and calculating the ESS of the entire system.

\subsection{Game Players and Model Assumptions}

3.1.1. Power Generators. Power generators seek to maximize profits, and they may increase their profits by violating market rules. Therefore, power generators may seek rents from the compliance department of the trading centre in order to obtain higher profits. The strategic choices of power generators are affected by the possible loss caused by violations, rent-seeking costs, and profits obtained from violations.

Power generators have bounded rationality, and their strategy set is \{compliance, noncompliance\}. We assume that the probability that the power generator chooses "noncompliance" strategy is $x(0 \leq x \leq 1)$. In order to maximize profits, power generators may adopt illegal operations and seek rents from the compliance department of the trading centre at the same time. The rent-seeking cost of the power generator is $R$. In addition, the power generator has to bear the psychological cost $E_{G}$ when it conducts rent-seeking behavior. If the compliance department of the trading centre accepts $R$ from the power generator, the power generator will obtain benefit $B$ from illegal operations. If the power generator chooses "compliance" strategy, the benefit is 0 . If the government regulatory agency discovers collusion between the compliance department of the trading centre and the power generator, both parties will be punished, and the fines imposed on the power generator are $T_{G}$. In addition, once the power generator's misdeeds are discovered, its market competitiveness would decline due to fierce competition in the power generation market. We assume that the power generator would lose $L_{G}$.

3.1.2. The Compliance Department of the Trading Centre. The compliance department of the trading centre is responsible for the compliance management of market members. It hopes to ensure market stability and maximize its reputation. However, if the inspection cost is too high, it will consider reducing the intensity of inspections and may even collude with power generators to increase profits.

The compliance department of the trading centre has bounded rationality, and its strategy set is \{strict inspection, lax inspection\}. The probability that the compliance department chooses lax inspection is $y(0 \leq y \leq 1)$. The costs of strict inspection and lax inspection are $C_{1}$ and $C_{2}$, respectively $\left(C_{1}>C_{2}\right)$. If the compliance department accepts rentseeking, it will bear the psychological cost $E_{D}$. If its collusion is discovered by the government regulatory agency, it would be fined $T_{D}\left(T_{D} \leq T_{G}\right)$. Worse still, the compliance department would suffer from reputation loss $L_{D}$. By contrast, if the compliance department adopts the "strict inspection" strategy and discovers rent-seeking behavior of the power generator, it would refuse rent $R$ and hand it over to the government regulatory agency. The government regulatory agency will fine the power generator. Meanwhile, the compliance department will benefit from the reputation gain
$F$. Generally speaking, $L_{D}$ caused by reputation damage is greater than the reputation gain $F\left(L_{D}>F\right)$.

3.1.3. The Government Regulatory Agency. The government regulatory agency supervises the compliance of all participants in the power market on behalf of the country and imposes penalties on violation. The government regulatory agency has bounded rationality, and their strategy set is \{supervision, nonsupervision\}. The probability that the government regulatory agency chooses supervision is $z$ $(0 \leq z \leq 1)$. The cost of supervision is $S$. If the government detects violations in the market, it will gain $G_{B}$ from prestige increase. The cost of nonsupervision is 0 . However, once the compliance department and the power generator succeed in collusion, the government regulatory agency would suffer from prestige decline and lose $G_{U}$.

The definition of each parameter is shown in Table 1.

3.2. Payoff Matrix. Since each player has two strategies, there are eight strategy combinations. If the power generator chooses the "compliance" strategy, it will get 0 , while the payoffs of the compliance department and the government regulatory agency depend on their strategies. The compliance department will get $-C_{1}$ if it chooses "strict inspection" strategy; otherwise, it will get $-C_{2}$. The government regulatory agency will get $-S$ if it chooses "supervision strategy" and get 0 , otherwise.

If the power generator chooses "noncompliance" strategy, it will bear psychological cost $E_{G}$. Under this situation, if the compliance department chooses "strict inspection" strategy, it will disclose the violation of the power generator and hand over the rent $R$ to the government regulatory agency. Hence, the power generator will get a fine $T_{G}$ and suffer from profit loss $L_{G}$. Therefore, the power generator's payoff is $-E_{G}-R-T_{G}-L_{G}$. The compliance department's payoff is $F-C_{1}$ as it will benefit from reputation rise and pay inspection costs. Given that the power generator chooses "noncompliance" strategy and the compliance department chooses "strict inspection" strategy, the government regulatory agency's payoff will be $R+T_{G}-S+G_{B}$ if it chooses "supervision strategy" and finds the violation of the power generator. Otherwise, its payoff will be $R+T_{G}$ since the violation of the power generator is disclosed by the compliance department, and thus, the violation does no harm to the government regulatory agency's prestige.

If the power generator chooses "noncompliance" strategy and the compliance department chooses "lax inspection" strategy, the violation and rent-seeking behavior of the power generator will not be disclosed by the compliance department. Under this circumstance, the government regulatory agency will find the violation and fine both the power generator and the compliance department if it adopts "supervision" strategy. The power generator's payoff will be $B-E_{G}-R-T_{G}-L_{G}$ as it gets profits $B$ and pays psychological costs $E_{G}$, rent-seeking cost $R$, fine tickets $T_{G}$, and competitiveness loss $L_{G}$. The compliance department's payoff will be $R-E_{D}-C_{2}-T_{D}-L_{D}$ as it gets rent $R$ and pays psychological costs $E_{D}$, lax inspection costs $C_{2}$, fine 
TABle 1: Notation.

\begin{tabular}{lrc}
\hline Parameters & Descriptions & Range \\
\hline$x$ & Probability of noncompliance of the power generator & $0 \leq x \leq 1$ \\
$y$ & Probability of lax inspection of the compliance department & $0 \leq y \leq 1$ \\
$z$ & Probability of supervision of the government regulatory agency & $0 \leq z \leq 1$ \\
$C_{1}$ & Strict inspection costs of the compliance department & $C_{1}>C_{2}>0$ \\
$C_{2}$ & Lax inspection costs of the compliance department & $C_{1}>C_{2}>0$ \\
$E_{G}$ & Psychological cost of the power generator & $E_{G}>0$ \\
$E_{D}$ & Psychological cost of the compliance department & $E_{D}>0$ \\
$B$ & Benefits of noncompliance of the power generator & $B>0$ \\
$R$ & Rent-seeking costs of the power generator & $R>0$ \\
$T_{G}$ & Fines imposed by the government regulatory agency on the power generator & $0<T_{D} \leq T_{G}$ \\
$T_{D}$ & Lines imposed by the government regulatory agency on the compliance department & $0<T_{D} \leq T_{G}$ \\
$L_{G}$ & Losses suffered by the power generator after its violations are revealed & $L_{G}>0$ \\
$L_{D}$ & Losses suffered by the compliance department after its violations are revealed & $L_{D}>F>0$ \\
$F$ & Reputation gains of the compliance department by disclosing rent-seeking behavior of the power generator & $L_{D}>F>0$ \\
$S$ & Supervision costs of the government regulatory agency & $S>0$ \\
$G_{B}$ & Benefits from prestige increase of the government regulatory agency & $G_{U}>G_{B}>0$ \\
$G_{U}$ & Losses of prestige after failing to discover market violations & $G_{U}>G_{B}>0$ \\
\hline
\end{tabular}

tickets $T_{D}$, and reputation loss $L_{D}$. The government regulatory agency's payoff will be $T_{D}+T_{G}+G_{B}-S$ as it receives fines $T_{D}$ and $T_{G}$ and gets $G_{B}$ from prestige increase. If the government regulatory agency adopts "nonsupervision" strategy, it will fail to find market violations and suffer from prestige decline. Thus, the government regulatory agency's payoff will be $-G_{U}$. The payoffs of the power generator and the compliance department are $\mathrm{B}-E_{G}-R, R-E_{D}-C_{2}$, respectively, since they collude with each other successfully. The payoff matrix is shown in Table 2.

3.3. Replicator Dynamic System. Suppose the expected payoffs of the power generator adopting "compliance" and "noncompliance" are $\pi_{1-x}$ and $\pi_{x}$, respectively. Then, we have

$$
\begin{aligned}
\pi_{1-x}= & 0, \\
\pi_{x}= & z\left[(1-y)\left(-E_{G}-R-T_{G}-L_{G}\right)+y\left(\mathrm{~B}-E_{G}-R-T_{G}-L_{G}\right)\right] \\
& +(1-z)\left[(1-y)\left(-E_{G}-R-T_{G}-L_{G}\right)+y\left(\mathrm{~B}-E_{G}-R\right)\right] \\
= & -E_{G}-R-T_{G}-L_{G}+y\left(\mathrm{~B}+T_{G}+L_{G}\right)+z y\left(-T_{G}-L_{G}\right) .
\end{aligned}
$$

Thus, the expected payoff of the power generator is

$$
\bar{\pi}_{G}=x \pi_{x}+(1-x) \pi_{1-x} .
$$

The replicator dynamic function of the strategy "noncompliance" is

$$
\begin{aligned}
G(x)=\frac{\mathrm{d} x}{\mathrm{~d} t}= & x\left(\pi_{x}-\bar{\pi}_{G}\right) \\
= & x(1-x)\left[-E_{G}-R-T_{G}-L_{G}+y\left(\mathrm{~B}+T_{G}+L_{G}\right)\right. \\
& \left.+z y\left(-T_{G}-L_{G}\right)\right] .
\end{aligned}
$$

Likewise, suppose the expected payoffs of the compliance department adopting "strict inspection" and "lax inspection" are $\pi_{1-y}$ and $\pi_{y}$, respectively. Then, we have

$$
\begin{aligned}
\pi_{1-y}= & (1-x)\left(-C_{1}\right)+x\left(F-C_{1}\right)=x F-C_{1}, \\
\pi_{y}= & (1-x)\left(-C_{2}\right)+x\left[z\left(R-E_{D}-C_{2}-T_{D}-L_{D}\right)\right. \\
& \left.+(1-z)\left(R-E_{D}-C_{2}\right)\right] \\
= & -C_{2}+z x\left(-T_{D}-L_{D}\right)+x\left(R-E_{D}\right) .
\end{aligned}
$$
is

Thus, the expected payoff of the compliance department

$$
\bar{\pi}_{D}=y \pi_{y}+(1-y) \pi_{1-y} .
$$

The replicator dynamic function of the strategy "lax inspection" is

$$
\begin{aligned}
D(y)=\frac{\mathrm{d} y}{\mathrm{~d} t}= & y\left(\pi_{y}-\bar{\pi}_{D}\right) \\
= & y(1-y)\left[-C_{2}+z x\left(-T_{D}-L_{D}\right)\right. \\
& \left.+x\left(R-E_{D}\right)-x F+C_{1}\right] \\
= & y(1-y)\left[C_{1}-C_{2}+x\left(R-E_{D}-F-z\left(T_{D}+L_{D}\right)\right)\right] .
\end{aligned}
$$

Similarly, suppose the expected payoffs of the government regulatory agency adopting "supervision" and "nonsupervision" are $\pi_{z}$ and $\pi_{1-z}$, respectively. Then, we have

$$
\begin{aligned}
\pi_{z}= & (1-x)(-S)+x\left[(1-y)\left(R+T_{G}-S+G_{B}\right)\right. \\
& \left.+y\left(T_{D}+T_{G}+G_{B}-S\right)\right] \\
= & -S+x\left[(1-y) R+T_{G}+G_{B}+y T_{D}\right], \\
\pi_{1-z}= & x\left[(1-y)\left(R+T_{G}\right)+y\left(-G_{U}\right)\right] .
\end{aligned}
$$

Thus, the expected payoff of the government regulatory agency is

$$
\bar{\pi}_{I}=z \pi_{z}+(1-z) \pi_{1-z} .
$$

The replicator dynamic function of the strategy "supervision" is 
TABle 2: Payoff matrix of the game.

\begin{tabular}{|c|c|c|c|}
\hline \multicolumn{4}{|c|}{ The government regulatory agency } \\
\hline $\begin{array}{l}\text { The power } \\
\text { generator }\end{array}$ & $\begin{array}{c}\text { The compliance department of the } \\
\text { trading centre }\end{array}$ & Supervision $z$ & Nonsupervision $1-z$ \\
\hline Compliance $1-x$ & $\begin{array}{l}\text { Strict inspection } 1-y \\
\text { Lax inspection } y\end{array}$ & $\begin{array}{r}0,-C_{1},-S \\
0,-C_{2},-S\end{array}$ & $\begin{array}{l}0,-C_{1}, 0 \\
0,-C_{2}, 0\end{array}$ \\
\hline Noncompliance $x$ & $\begin{array}{l}\text { Strict inspection } 1-y \\
\text { Lax inspection } y\end{array}$ & $\begin{array}{c}-E_{G}-R-T_{G}-L_{G}, F-C_{1}, R+T_{G}-S+G_{B} \\
\mathrm{~B}-E_{G}-R-T_{G}-L_{G}, R-E_{D}-C_{2}-T_{D}-L_{D} \\
T_{D}+T_{G}+G_{B}-S\end{array}$ & $\begin{array}{c}-E_{G}-R-T_{G}-L_{G}, F-C_{1}, \\
R+T_{G} \\
\text { B- } E_{G}-R, R-E_{D}-C_{2} \\
-G_{U}\end{array}$ \\
\hline
\end{tabular}

$$
\begin{aligned}
I(z)= & \frac{\mathrm{d} z}{d t}=z\left(\pi_{z}-\bar{\pi}_{I}\right) \\
= & z(1-z)\left\{\left[-S+x\left((1-y) R+T_{G}+G_{B}+y T_{D}\right)\right]\right. \\
& \left.-x\left[(1-y)\left(R+T_{G}\right)+y\left(-G_{U}\right)\right]\right\} \\
= & z(1-z)\left[-S+x G_{B}+x y\left(T_{G}+T_{D}+G_{U}\right)\right] .
\end{aligned}
$$

\subsection{Evolutionary Stable Strategy Analysis}

3.4.1. Evolutionary Stable Strategy of the Power Generator. Based on the replicator dynamic function of the strategy "noncompliance," we have the first derivative of $G(x)$ :

$$
\begin{aligned}
\frac{\mathrm{d} G(x)}{\mathrm{d} x}= & (1-2 x)\left[-E_{G}-R-T_{G}-L_{G}+y\left(B+T_{G}+L_{G}\right)\right. \\
& \left.+z y\left(-T_{G}-L_{G}\right)\right] .
\end{aligned}
$$

According to the Friedman method, when $G(x)=0$ and $(\mathrm{d} G(x) / \mathrm{d} x)<0, x$ is an evolutionary stable strategy (ESS). When $z=\left(E_{G}+R+T_{G}+L_{G}-y\left(\mathrm{~B}+T_{G}+L_{G}\right) / y\left(-T_{G}-\right.\right.$ $\left.\left.L_{G}\right)\right), G(x) \equiv 0$ and $(\mathrm{d} G(x) / \mathrm{d} x) \equiv 0, x$ is an ESS for all $x$ that satisfy $x \geq 0$. That is to say, when the probability that the government regulatory agency chooses "supervision" strategy $\left(E_{G}+R+T_{G}+L_{G}-y\left(\mathrm{~B}+T_{G}+L_{G}\right) / y\left(-T_{G}-L_{G}\right)\right)$, the probability of the power generator choosing "noncompliance" strategy is stable.

(1) When $z \neq\left(E_{G}+R+T_{G}+L_{G}-y\left(\mathrm{~B}+T_{G}+L_{G}\right) / y\right.$ $\left.\left(-T_{G}-L_{G}\right)\right)$, let $G(x)=0$; we have $x=0$ and $x=1$ are the two stable solutions of $x$. Thus, the following two situations need to be discussed.

(2) When $z>\left(E_{G}+R+T_{G}+L_{G}-y\left(B+T_{G}+L_{G}\right) / y\right.$ $\left.\left(-T_{G}-L_{G}\right)\right)$, we have $\left.(\mathrm{d} G(x) / \mathrm{d} x)\right|_{x=0}<0$ and $\left.(\mathrm{d} G(x) / \mathrm{d} x)\right|_{x=1}<0$. At this point, $x=0$ is an ESS, that is, when government supervision is strong enough, the optimal strategy for the power generator is "compliance" even if the compliance department of the trading centre chooses "lax inspection."

(2) When $\quad z<\left(E_{G}+R+T_{G}+L_{G}-y\left(\mathrm{~B}+T_{G}+\right.\right.$ $\left.\left.L_{G}\right) / y\left(-T_{G}-L_{G}\right)\right)$, we have $\left.(\mathrm{d} G(x) / \mathrm{d} x)\right|_{x=0}<0$ and $\left.(\mathrm{d} G(x) / \mathrm{d} x)\right|_{x=1}<0$. At this point, $x=1$ is an ESS, that is, when government supervision is weak enough and the compliance department chooses "lax inspection," the optimal strategy for the power generator is "noncompliance."

3.4.2. Evolutionary Stable Strategy of the Compliance Department. Similarly, based on the replicator dynamic function of the strategy "lax inspection," we have the first derivative of $D(y)$ :

$\frac{\mathrm{d} D(y)}{\mathrm{d} y}=(1-2 y)\left[C_{1}-C_{2}+x\left(R-E_{D}-F-z\left(T_{D}+L_{D}\right)\right)\right]$.

(1) When $\quad x=\left(C_{1}-C_{2} / z\left(T_{D}+L_{D}\right)-R+E_{D}+F\right)$, $D(y) \equiv 0$, and $(\mathrm{d} D(y) / \mathrm{d} y) \equiv 0, y$ is an ESS for all $y$ that satisfy $y \geq 0$. That is to say, when the probability that the power generator chooses "noncompliance" strategy is $\left(C_{1}-C_{2} / z\left(T_{D}+L_{D}\right)-R+E_{D}+F\right)$, the probability of the compliance department choosing "lax inspection" strategy is stable.

(2) When $x \neq\left(C_{1}-C_{2} / z\left(T_{D}+L_{D}\right)-R+E_{D}+F\right)$, let $D(y)=0$; we have $y=0$ and $y=1$ are the two stable solutions of $y$. Thus, the following two situations need to be discussed.

(3) When $x>\left(C_{1}-C_{2} / z\left(T_{D}+L_{D}\right)-R+E_{D}+F\right)$, we have $\left.(\mathrm{d} D(y) / \mathrm{d} y)\right|_{y=0}<0$ and $\left.(\mathrm{d} D(y) / \mathrm{d} y)\right|_{y=1}<0$. At this point, $y=0$ is an ESS, that is, when the probability that the power generator chooses "noncompliance" strategy is high enough, the compliance department will choose "strict inspection" strategy.

(4) When $x<\left(C_{1}-C_{2} / z\left(T_{D}+L_{D}\right)-R+E_{D}+F\right)$, we have $\left.(\mathrm{d} D(y) / \mathrm{d} y)\right|_{y=0}<0$ and $\left.(\mathrm{d} D(y) / \mathrm{d} y)\right|_{y=1}<0$. At this point, $y=1$ is an ESS, that is, when the probability that the power generator chooses "noncompliance" strategy is below a certain value, the compliance department will choose "lax inspection" strategy.

3.4.3. Evolutionary Stable Strategy of the Government Regulatory Agency. Based on the replicator dynamic function of the strategy "lax inspection," we have the first derivative of $I(z)$ : 


$$
\frac{\mathrm{d} I(z)}{\mathrm{d} z}=(1-2 z)\left[-S+x G_{B}+x y\left(T_{G}+T_{D}+G_{U}\right)\right] .
$$

(1) When $y=\left(S-x G_{B} / x\left(T_{G}+T_{D}+G_{U}\right)\right), \quad I(z) \equiv 0$, and $(\mathrm{d} I(z) / \mathrm{d} z) \equiv 0, z$ is an ESS for all $z$ that satisfy $z \geq 0$. That is to say, when the probability that the compliance department chooses "lax inspection" strategy is $\left(S-x G_{B} / x\left(T_{G}+T_{D}+G_{U}\right)\right)$, the probability of the government regulatory agency choosing "supervision" strategy is stable.

(2) When $y \neq\left(S-x G_{B} / x\left(T_{G}+T_{D}+G_{U}\right)\right)$, let $I(z)=0$; we have $z=0$ and $z=1$ are the two stable solutions of $z$. Thus, the following two situations need to be discussed.

(3) When $y>\left(S-x G_{B} / x\left(T_{G}+T_{D}+G_{U}\right)\right)$, we have $\left.(\mathrm{d} I(z) / \mathrm{d} z)\right|_{z=0}>0$ and $\left.(\mathrm{d} I(z) / \mathrm{d} z)\right|_{z=1}>0$. At this point, $z=1$ is an ESS, that is, when the probability that the compliance department is negligent, the government regulatory agency will choose "supervision" strategy.

(4) When $y<\left(S-x G_{B} / x\left(T_{G}+T_{D}+G_{U}\right)\right)$, we have $\left.(\mathrm{d} I(z) / \mathrm{d} z)\right|_{z=0}>0$ and $\left.(\mathrm{d} I(z) / \mathrm{d} z)\right|_{z=1}>0$. At this point, $z=0$ is an ESS, that is, when the compliance department does its due diligence, the government regulatory agency will choose "nonsupervision" strategy.

\subsection{Evolutionary Stable Strategy of the Replicator Dynamic} System. We can get the equilibrium points $(x, y, z) \in[0,1] \times[0,1] \times[0,1]$ based on the replicator dynamic functions obtained above. The equilibrium points should satisfy the following equations:

$$
\left\{\begin{array}{l}
x(1-x)\left[-E_{G}-R-T_{G}-L_{G}+y\left(B+T_{G}+L_{G}\right)+z y\left(-T_{G}-L_{G}\right)\right]=0 \\
y(1-y)\left[C_{1}-C_{2}+x\left(R-E_{D}-F-z\left(T_{D}+L_{D}\right)\right)\right]=0 \\
z(1-z)\left[-S+x G_{B}+x y\left(T_{G}+T_{D}+G_{U}\right)\right]=0 .
\end{array}\right.
$$

Solving the above equations, we can obtain 9 equilibrium points: $\mathrm{A}(0,0,0), \mathrm{B}(0,1,0), \mathrm{C}(0,0,1), \mathrm{D}(1,0,0), \mathrm{E}(1,1,0)$, $\mathrm{F}(1,1,1), \mathrm{G}(1,0,1), \mathrm{H}(0,1,1)$, and $\mathrm{I}\left(x^{*}, y^{*}, z^{*}\right)$ which is not a strict Nash equilibrium. In the evolutionary game, a Nash equilibrium is stable if and only if it is strict [20]. Thus, we only need to consider points $\mathrm{A}-\mathrm{H}$.

According to Friedman's law, the stability of the evolutionary equilibrium points can be derived from the stability analysis of the Jacobian matrix. The Jacobian matrix is a matrix arranged in a certain way by the first-order partial derivatives. It is a matrix that can reflect the optimal linear approximation of a certain equation to a given point. This paper adopts the criterion of ESS for local equilibrium points proposed by Friedman [21], i.e., the determinant of the Jacobian matrix is greater than zero, and the trace is less than zero.

The Jacobian matrix of the replicator dynamic system is shown in the following:

$$
\begin{aligned}
J & =\left[\begin{array}{l}
\frac{\partial G(x)}{\partial x} \frac{\partial G(x)}{\partial z} \frac{\partial G(x)}{\partial z} \\
\frac{\partial D(y)}{\partial x} \frac{\partial D(y)}{\partial z} \frac{\partial D(y)}{\partial z} \\
\frac{\partial I(z)}{\partial x} \frac{\partial I(z)}{\partial z} \frac{\partial I(z)}{\partial z}
\end{array}\right] \\
& =\left[\begin{array}{ccc}
(1-2 x)\left[-E_{G}-R-T_{G}-L_{G}+y\left(B+T_{G}+L_{G}\right)+z y\left(-T_{G}-L_{G}\right)\right] & x(1-x)\left[\left(B+T_{G}+L_{G}\right)-z\left(T_{G}+L_{G}\right)\right] & x(1-x)\left(-T_{G}-L_{G}\right) \\
y(1-y)\left[R-E_{D}-F-Z\left(T_{D}-L_{D}\right)\right] & (1-2 y)\left[C_{1}-C_{2}+x\left(R-E_{D}-F-Z\left(T_{D}-L_{D}\right)\right)\right] & y(1-y) x\left(-T_{D}-L_{D}\right) \\
Z(1-Z)\left[G_{B}+y\left(T_{G}+T_{D}+G_{U}\right)\right] & Z(1-Z) x\left(T_{G}+T_{D}+G_{U}\right) & (1-2 z)\left[-S+x G_{B}+x y\left(T_{G}+T_{D}+G_{U}\right)\right]
\end{array}\right] .
\end{aligned}
$$


The stability of the equilibrium points $\mathrm{A}(0,0,0), \mathrm{B}(0,1$, $0), \mathrm{C}(0,0,1), \mathrm{D}(1,0,0), \mathrm{E}(1,1,0), \mathrm{F}(1,1,1), \mathrm{G}(1,0,1)$, and $\mathrm{H}(0,1,1)$ is analyzed, respectively.

3.5.1. $A(0,0,0)$. The Jacobian matrix at equilibrium point $\mathrm{A}$ $(0,0,0)$ is shown as follows:

$$
J=\left[\begin{array}{ccc}
-E_{G}-R-T_{G}-L_{G} & 0 & 0 \\
0 & C_{1}-C_{2} & 0 \\
0 & 0 & -S
\end{array}\right]
$$

Thus, we have

$$
\begin{aligned}
\operatorname{det} J & =S\left(E_{G}+R+T_{G}+L_{G}\right)\left(C_{1}-C_{2}\right), \\
\operatorname{tr} J & =-E_{G}-R-T_{G}-L_{G}+C_{1}-C_{2}-S .
\end{aligned}
$$

Apparently, $\operatorname{det} J>0$ and $\operatorname{tr} J<0$ if $C_{1}-C_{2}<E_{G}+$ $R+T_{G}+L_{G}+S$. Therefore, A $(0,0,0)$ is an ESS if $C_{1}-C_{2}<E_{G}+R+T_{G}+L_{G}+S$.

3.5.2. $B(0,1,0)$. The Jacobian matrix at equilibrium point $B$ $(0,1,0)$ is shown as follows:

$$
J=\left[\begin{array}{ccc}
-E_{G}-R+B & 0 & 0 \\
0 & C_{1}-C_{2} & 0 \\
0 & 0 & -S
\end{array}\right]
$$

Thus, we have

$$
\begin{aligned}
\operatorname{det} J & =S\left(E_{G}+R-B\right)\left(C_{1}-C_{2}\right), \\
\operatorname{tr} J & =-E_{G}-R+B+C_{1}-C_{2}-S .
\end{aligned}
$$

Apparently, det $J>0$ and $\operatorname{tr} J<0$ if $E_{G}+R-B>0$ and $C_{1}-C_{2}<E_{G}+R-B+S$. Therefore, $\mathrm{B}(0,1,0)$ is an ESS if $E_{G}+R-B>0$ and $C_{1}-C_{2}<E_{G}+R-B+S$.

3.5.3. $C(0,0,1)$. The Jacobian matrix at equilibrium point $C$ $(0,0,1)$ is shown as follows:

$$
J=\left[\begin{array}{ccc}
-E_{G}-R-T_{G}-L_{G} & 0 & 0 \\
0 & C_{1}-C_{2} & 0 \\
0 & 0 & S
\end{array}\right]
$$

Thus, we have

$$
\begin{aligned}
\operatorname{det} J & =S\left(-E_{G}-R-T_{G}-L_{G}\right)\left(C_{1}-C_{2}\right), \\
\operatorname{tr} J & =-E_{G}-R-T_{G}-L_{G}+C_{1}-C_{2}+S .
\end{aligned}
$$

Apparently, $\operatorname{det} J<0$, but the sign of $\operatorname{tr} J$ is undetermined. Therefore, $C(0,0,1)$ is a saddle point.

3.5.4. $\mathrm{D}(1,0,0)$. The Jacobian matrix at equilibrium point $\mathrm{D}$ $(1,0,0)$ is shown as follows:

$$
J=\left[\begin{array}{ccc}
E_{G}+R+T_{G}+L_{G} & 0 & 0 \\
0 & C_{1}-C_{2}+R-E_{D}-F & 0 \\
0 & 0 & G_{B}-S
\end{array}\right] .
$$

Thus, we have

$$
\begin{aligned}
\operatorname{det} J & =\left(E_{G}+R+T_{G}+L_{G}\right)\left(C_{1}-C_{2}+R-E_{D}-F\right)\left(G_{B}-S\right), \\
\operatorname{tr} J & =E_{G}+R+T_{G}+L_{G}+C_{1}-C_{2}+R-E_{D}-F+G_{B}-S .
\end{aligned}
$$

As $S, E_{G}, E_{D}, G_{B}, R, T_{G}, L_{G}>0$ and $C_{1}>C_{2}>0$, the stability of this point needs to be discussed in four cases. The results are shown in Table 3 . Thus, $\mathrm{D}(1,0,0)$ is an ESS under certain conditions in the fourth case.

3.5.5. $E(1,1,0)$. The Jacobian matrix at equilibrium point $\mathrm{E}$ $(1,1,0)$ is shown in the following:

$$
J=\left[\begin{array}{ccc}
E_{G}+R-B & 0 & 0 \\
0 & -\left(C_{1}-C_{2}+R-E_{D}-F\right) & 0 \\
0 & 0 & G_{B}-S+T_{G}+T_{D}+G_{U}
\end{array}\right] .
$$

Thus, we have

$$
\begin{aligned}
\operatorname{det} J= & \left(E_{G}+R-B\right)\left(C_{2}-C_{1}-R+E_{D}+F\right)\left(G_{B}-S\right. \\
& \left.+T_{G}+T_{D}+G_{U}\right), \\
\operatorname{tr} J= & E_{G}+R-B+\left(C_{2}-C_{1}-R+E_{D}+F\right) \\
& +G_{B}-S+T_{G}+T_{D}+G_{U} .
\end{aligned}
$$

As $S, E_{G}, E_{D}, G_{B}, R, T_{G}, T_{D}, G_{U}>0$ and $C_{1}>C_{2}>0$, the stability of this point needs to be discussed in eight cases. The results are shown in Table 4 . Thus, $\mathrm{E}(1,1,0)$ is an ESS under certain conditions.

3.5.6. $F(1,1,1)$. The Jacobian matrix at equilibrium point $\mathrm{F}$ $(1,1,1)$ is shown in the following:

$$
J=\left[\begin{array}{ccc}
E_{G}+R+T_{G}+L_{G}-B & 0 & 0 \\
0 & T_{D}+L_{D}+E_{D}+F-C_{1}+C_{2} & 0 \\
0 & 0 & S-G_{B}-T_{G}-T_{D}-G_{U}
\end{array}\right]
$$


Table 3: Stability discussion of point D $(1,0,0)$.

\begin{tabular}{lccc}
\hline Condition & $\operatorname{det} J$ & $\operatorname{tr} J$ & Conclusion \\
\hline$C_{1}-C_{2}+R>E_{D}+F$ & + & + & Unstable \\
$G_{B}>S$ & - & Undetermined & Saddle point \\
$C_{1}-C_{2}+R>E_{D}+F ; G_{B}<S$ & - & Undetermined & Saddle point \\
$C_{1}-C_{2}+R<E_{D}+F ; G_{B}>S$ & + & - & ESS \\
$C_{1}-C_{2}+R<E_{D}+F ; G_{B}<S$ & + & \\
$E_{G}+R+T_{G}+L_{G}<S-G_{B}-\left(C_{1}-C_{2}+R-E_{D}-F\right)$ & & \\
\hline
\end{tabular}

TABLE 4: Stability discussion of point $\mathrm{E}(1,1,0)$.

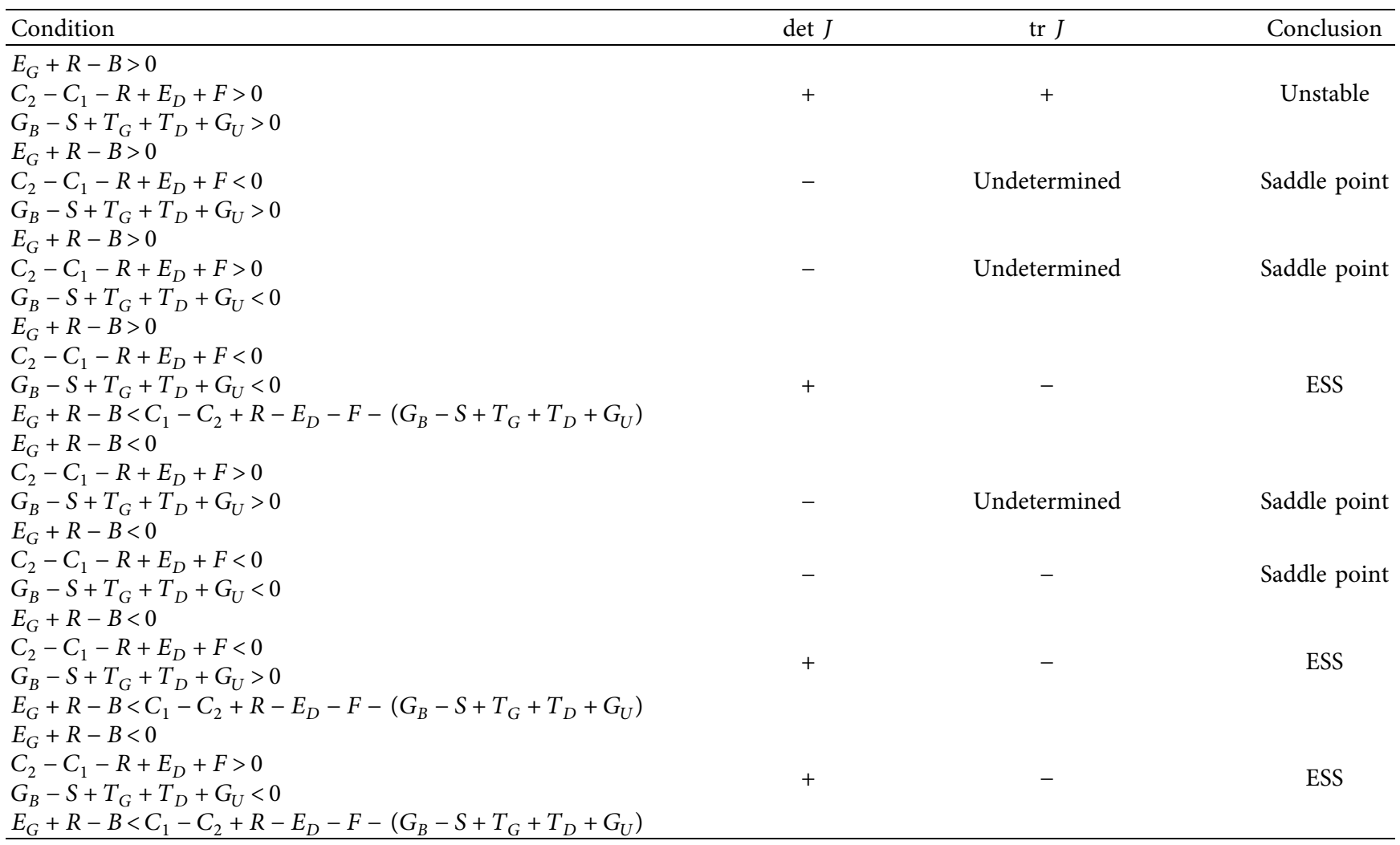

Thus, we have

$$
\begin{aligned}
\operatorname{det} J= & \left(E_{G}+R+T_{G}+L_{G}-B\right)\left(T_{D}+L_{D}+E_{D}\right. \\
& \left.+F-C_{1}+C_{2}\right) \times\left(S-G_{B}-T_{G}-T_{D}-G_{U}\right), \\
\operatorname{tr} J= & E_{G}+R+T_{G}+L_{G}-B+T_{D}+L_{D}+E_{D}+F-C_{1} \\
& +C_{2}+S-G_{B}-T_{G}-T_{D}-G_{U} .
\end{aligned}
$$

Since $S, E_{G}, E_{D}, G_{B}, R, T_{G}, L_{G}, B, T_{D}, L_{D}, G_{U}>0$ and $C_{1}>C_{2}>0$, the stability of this point needs to be discussed in eight cases which are shown in Table 5 . Thus, $F(1,1,1)$ is an ESS under certain conditions.

3.5.7. $G(1,0,1)$. The Jacobian matrix at equilibrium point $\mathrm{G}$ $(1,0,1)$ is shown in the following:

$$
J=\left[\begin{array}{ccc}
E_{G}+R+T_{G}+L_{G} & 0 & 0 \\
0 & C_{1}-C_{2}+R-E_{D}-F-T_{D}-L_{D} & 0 \\
0 & 0 & S-G_{B}
\end{array}\right]
$$


TABLE 5: Stability discussion of point $\mathrm{F}(1,1,1)$.

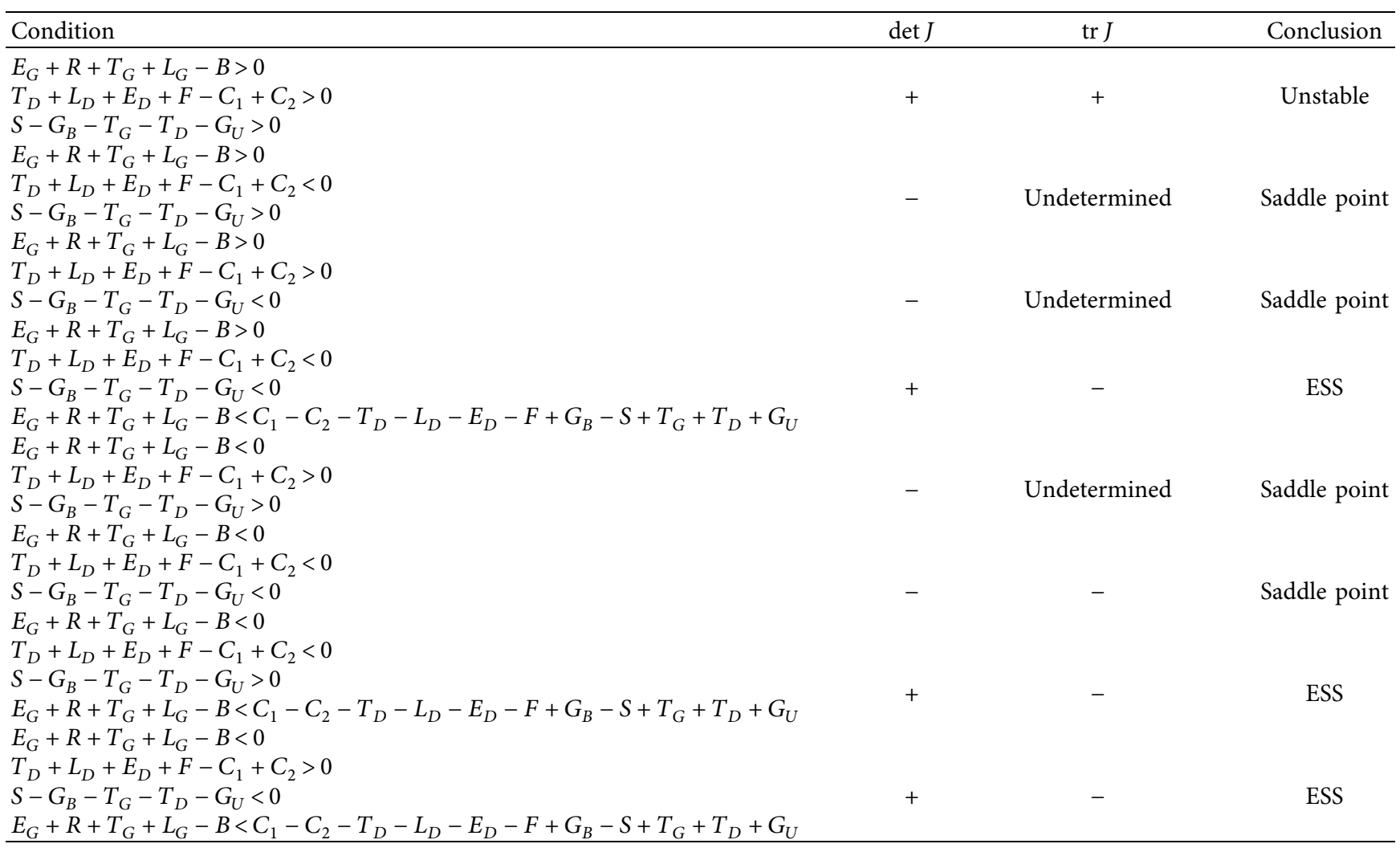

Table 6: Stability discussion of point $\mathrm{G}(1,0,1)$.

\begin{tabular}{lcc}
\hline Condition & det & tr $J$ \\
\hline$C_{1}-C_{2}+R>E_{D}+F+T_{D}+L_{D}$ & + & Conclusion \\
$S>G_{B}$ & - & Unstable \\
$C_{1}-C_{2}+R>E_{D}+F+T_{D}+L_{D}$ & Undetermined \\
$\mathrm{S}<G_{B}$ & & Saddle point \\
$C_{1}-C_{2}+R<E_{D}+F+T_{D}+L_{D}$ & - & Undetermined \\
$S>G_{B}$ & & Saddle point \\
$C_{1}-C_{2}+R<E_{D}+F+T_{D}+L_{D}$ & + & - \\
$S<G_{B}$ & & ESS \\
$E_{G}+R+T_{G}+L_{G}<G_{B}-S-\left(C_{1}-C_{2}+R-E_{D}-F-T_{D}-L_{D}\right)$ & \\
\hline
\end{tabular}

Thus, we have

$$
\begin{aligned}
\operatorname{det} J= & \left(E_{G}+R+T_{G}+L_{G}\right)\left(C_{1}-C_{2}\right. \\
& \left.+R-E_{D}-F-T_{D}-L_{D}\right)\left(S-G_{B}\right), \\
\operatorname{tr} J= & E_{G}+R+T_{G}+L_{G}+C_{1}-C_{2}+R-E_{D}-F \\
& -T_{D}-L_{D}+S-G_{B} .
\end{aligned}
$$

As $S, E_{G}, E_{D}, G_{B}, R, T_{G}, L_{G}, T_{D}, L_{D}, G_{B}>0$ and $C_{1}>C_{2}>$ 0 , the stability of this point needs to be discussed in four cases which are shown in Table 6 . Thus, $\mathrm{G}(1,0,1)$ is an ESS under certain conditions in the fourth case.

3.5.8. $H(0,1,1)$. The Jacobian matrix at equilibrium point $\mathrm{H}$ $(0,1,1)$ is shown in the following:

$$
J=\left[\begin{array}{ccc}
-E_{G}-R-T_{G}-L_{G}+B & 0 & 0 \\
0 & C_{2}-C_{1} & 0 \\
0 & 0 & S
\end{array}\right] .
$$

Thus, we have

$$
\begin{aligned}
\operatorname{det} J & =\left(-E_{G}-R-T_{G}-L_{G}+B\right)\left(C_{2}-C_{1}\right) S, \\
\operatorname{tr} J & =-E_{G}-R-T_{G}-L_{G}+B+C_{2}-C_{1}+S .
\end{aligned}
$$

Since $S, E_{G}, R, T_{G}, L_{G}, B>0$ and $C_{1}>C_{2}>0$, two cases are discussed which are shown in Table 7 . Thus, $H(0,1,1)$ is an ESS under certain conditions in the second case.

In summary, the equilibrium points $\mathrm{A}(0,0,0), \mathrm{B}(0,1,0)$, $\mathrm{D}(1,0,0), \mathrm{E}(1,1,0), \mathrm{F}(1,1,1), \mathrm{G}(1,0,1)$, and $\mathrm{H}(0,1,1)$ are all possible evolutionary stable strategies. 
TABle 7: Stability discussion of point $H(1,0,1)$.

\begin{tabular}{lccc}
\hline Condition & $\operatorname{det} J$ & $\operatorname{tr} J$ & Conclusion \\
\hline$B>E_{G}+R+T_{G}+L_{G}$ & - & Undetermined & Saddle point \\
$B<E_{G}+R+T_{G}+L_{G}$ & + & - & ESS \\
$C_{2}-C_{1}+S<E_{G}+R+T_{G}+L_{G}-B$ & & & \\
\hline
\end{tabular}

TABLE 8: The value of parameters.

\begin{tabular}{lcc}
\hline Parameters & Descriptions & Values \\
\hline$C_{1}$ & Strict inspection cost of the compliance department & 1.0 \\
$C_{2}$ & Lax inspection cost of the compliance department & 0.5 \\
$E_{G}$ & Psychological cost of the power generator & 0.5 \\
$E_{D}$ & Psychological cost of the compliance department & 0.6 \\
$B$ & Benefits of noncompliance of the power generator & 3.7 \\
$R$ & Rent-seeking costs of the power generator & 1.3 \\
$T_{G}$ & Fines imposed by the government regulatory agency on the power generator \\
$T_{D}$ & Fines imposed by the government regulatory agency on the compliance department \\
$L_{G}$ & Losses suffered by the power generator after its violations are revealed & 1.2 \\
$L_{D}$ & Losses suffered by the compliance department after its violations are revealed & \\
$F$ & Reputation gains of the compliance department by disclosing rent-seeking behaviors of the power generator & 0.7 \\
$S$ & Supervision costs of the government regulatory agency & 0.5 \\
$G_{B}$ & Benefits from prestige increase of the government regulatory agency & 0.9 \\
$G_{U}$ & Losses of prestige after failing to discover market violations & 0.3 \\
\hline
\end{tabular}

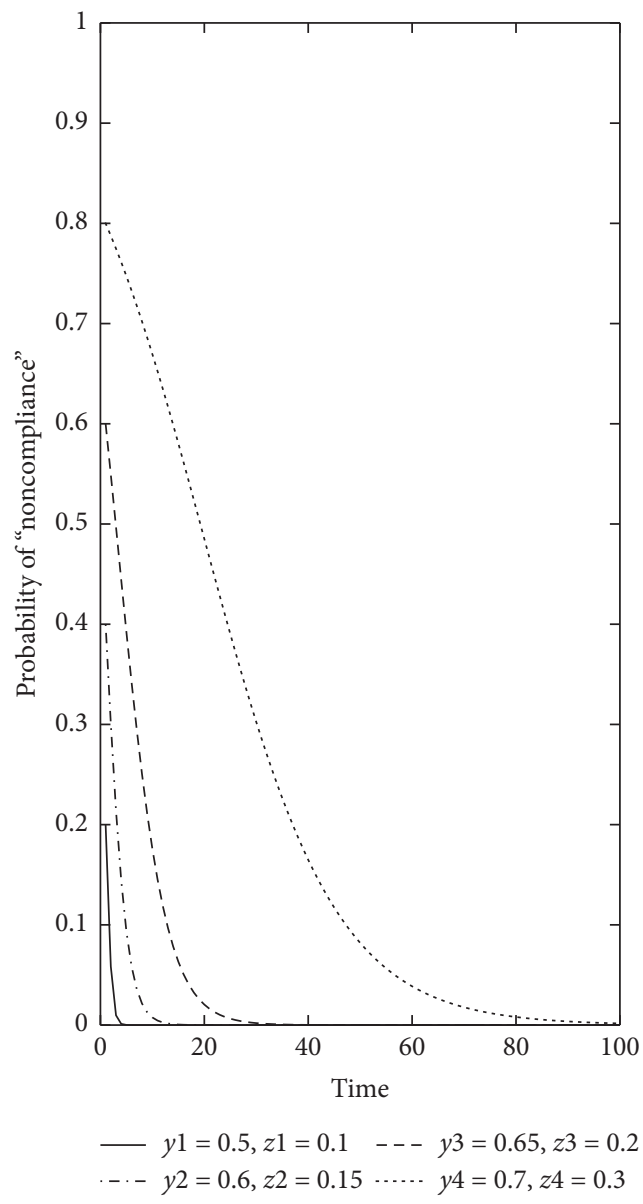

(a)

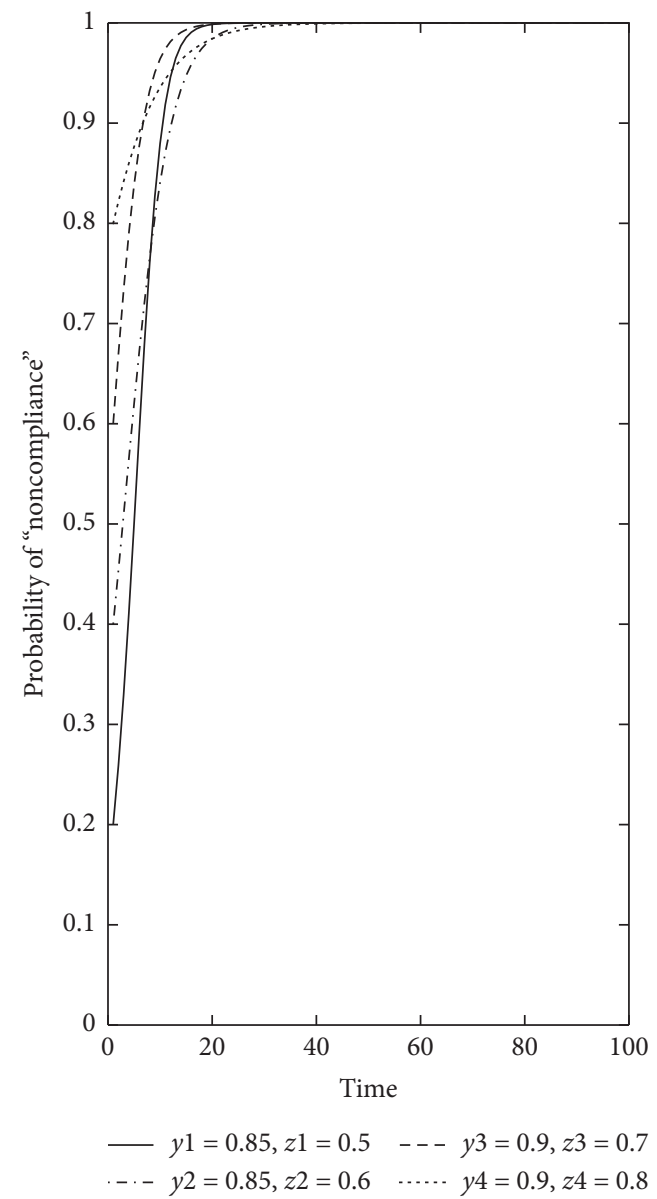

(b)

FIgURE 1: Evolutionary process of the power generator. 


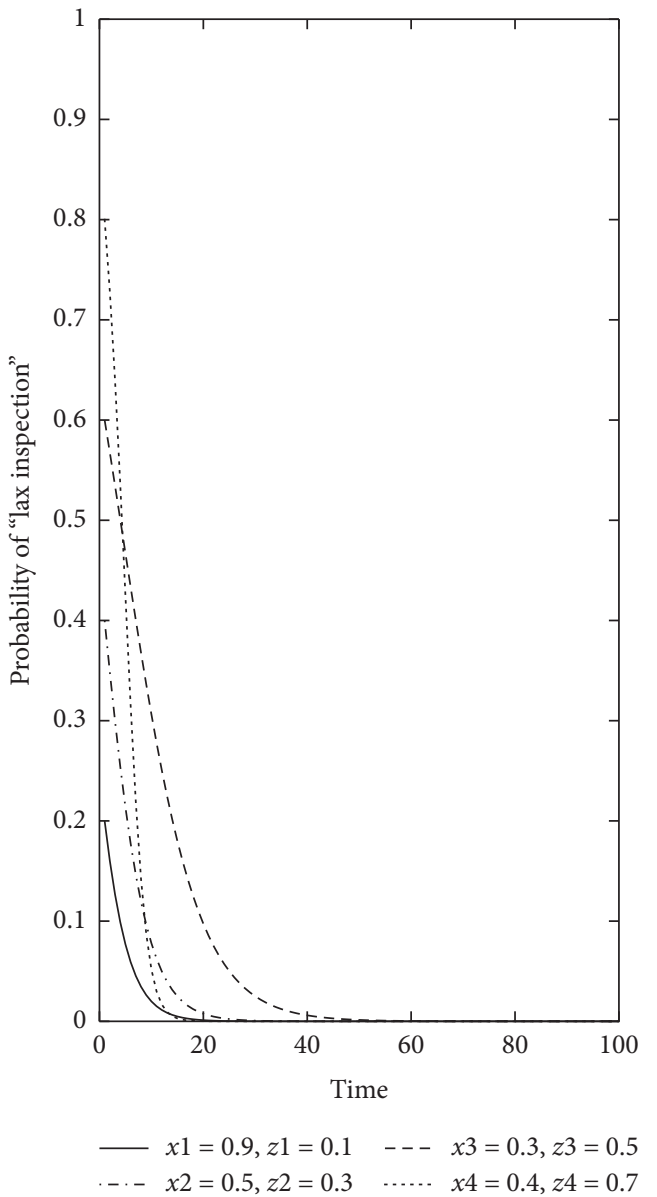

(a)

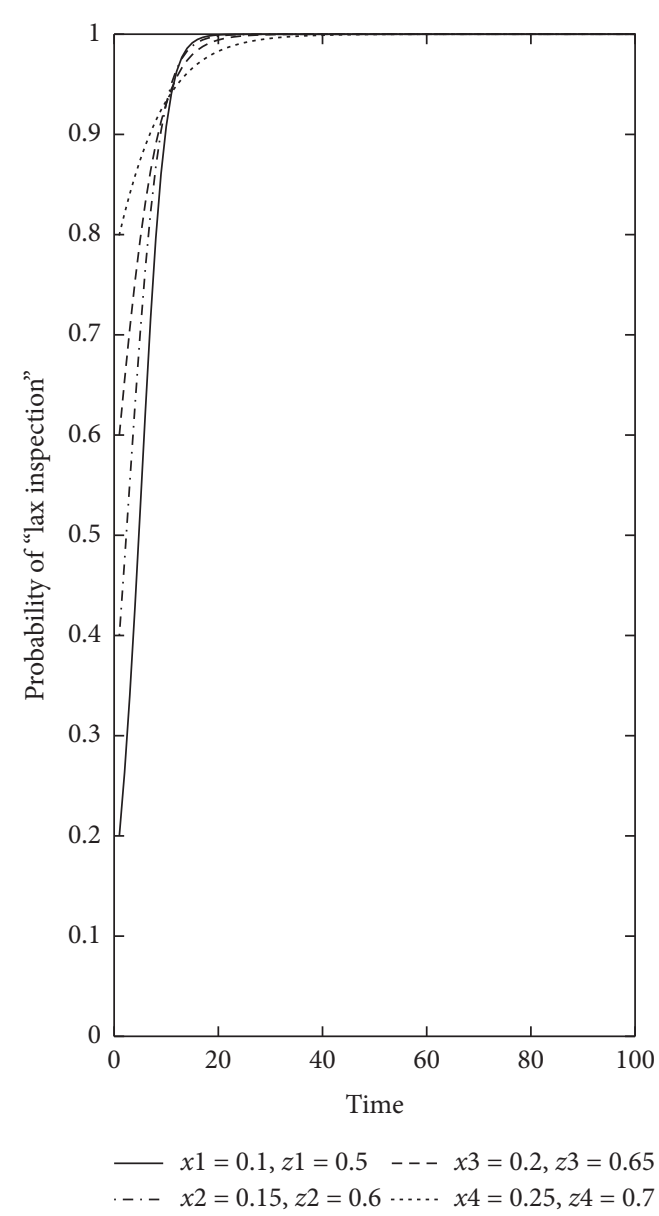

(b)

FIGURE 2: Evolutionary process of the compliance department.

\section{Simulation}

According to the results of the tripartite evolutionary game model, if the government does not regulate the market, power generators may not necessarily adopt "compliance" strategies in equilibrium, and the compliance department may not conduct "strict inspection." Therefore, the government regulatory agency shall take certain measures to establish the compliance management system for the electricity market, improving the compliance management mechanism and risk prevention to ensure the safe and standardized operation of the electricity market.

Ideally, the long-term equilibrium of the electricity market is at point $\mathrm{A}(0,0,0)$. In this state, the compliance management system is perfect, and the compliance department of the trading centre plays a supervisory role, so there is no need for the government regulatory agency to supervise the market participants. Power generators will consciously choose "compliance" strategy. The power of the electricity market is fully utilized so that the market can maximize the efficiency of compliance management at the minimum cost, but this equilibrium condition must be satisfied under the premise of $C_{1}-C_{2}<E_{G}+R+T_{G}+$ $L_{G}+S$. Therefore, we conduct simulation study on point $\mathrm{A}$
$(0,0,0)$ and further analyze its influencing factors. The parameters are randomly assigned according to the equilibrium conditions which are shown in Table 8.

4.1. Analysis of the Evolutionary Results. In order to make the analysis clearer, we simulated the strategic behaviors of the power generator, the compliance department, and the government regulatory agency, respectively. Furthermore, we simulated the evolutionary and stable solutions of the entire game system.

Firstly, $x$ is fixed, and four groups of different values satisfying the conditions are selected for $y$ and $z$, respectively. The results are shown in Figure 1. It can be seen from the figure that the choices of the power generator vary due to the different combinations of the strategies of the compliance department and the government regulatory agency. Figure 1(a) meets the condition of $z>\left(E_{G}+R+T_{G}+L_{G}-y\left(B+T_{G}+L_{G}\right) / y\left(-T_{G}-L_{G}\right)\right)$, while Figure 1(b) meets the condition of $z<\left(E_{G}+R+T_{G}+L_{G}-y\left(B+T_{G}+L_{G}\right) / y\left(-T_{G}-L_{G}\right)\right)$. It can be seen from the evolution results that when the probability of the compliance department choosing "strict inspection" is high, even if the probability of government 


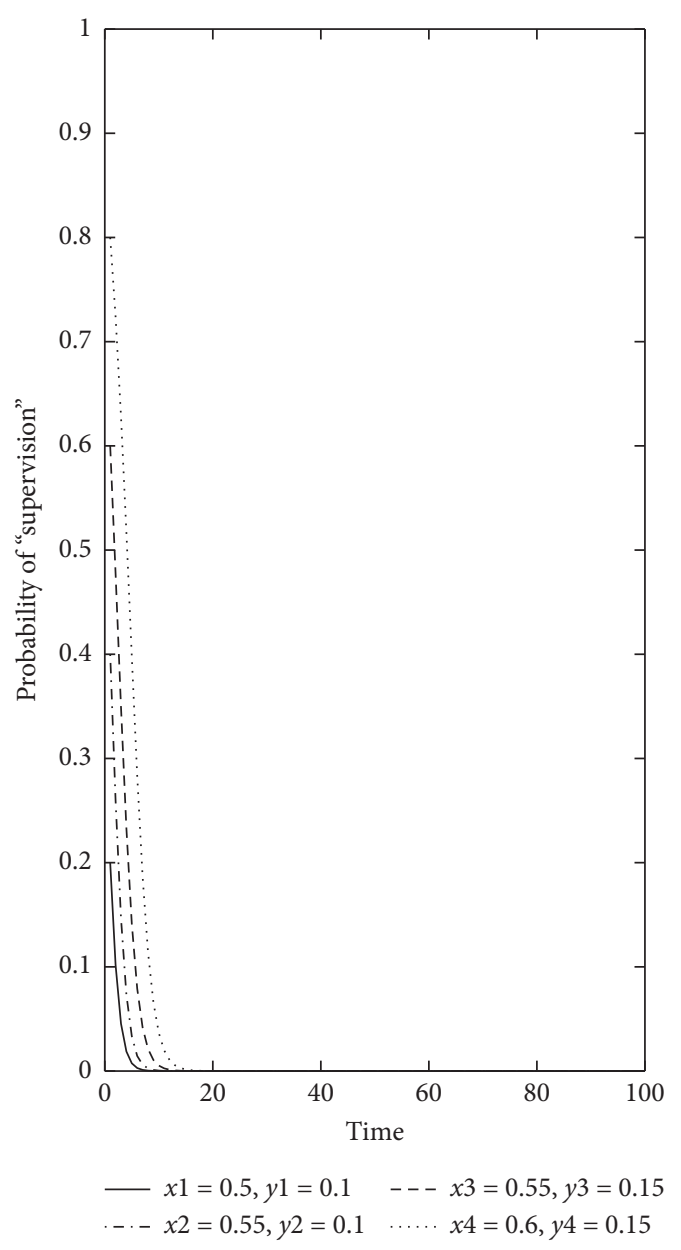

(a)

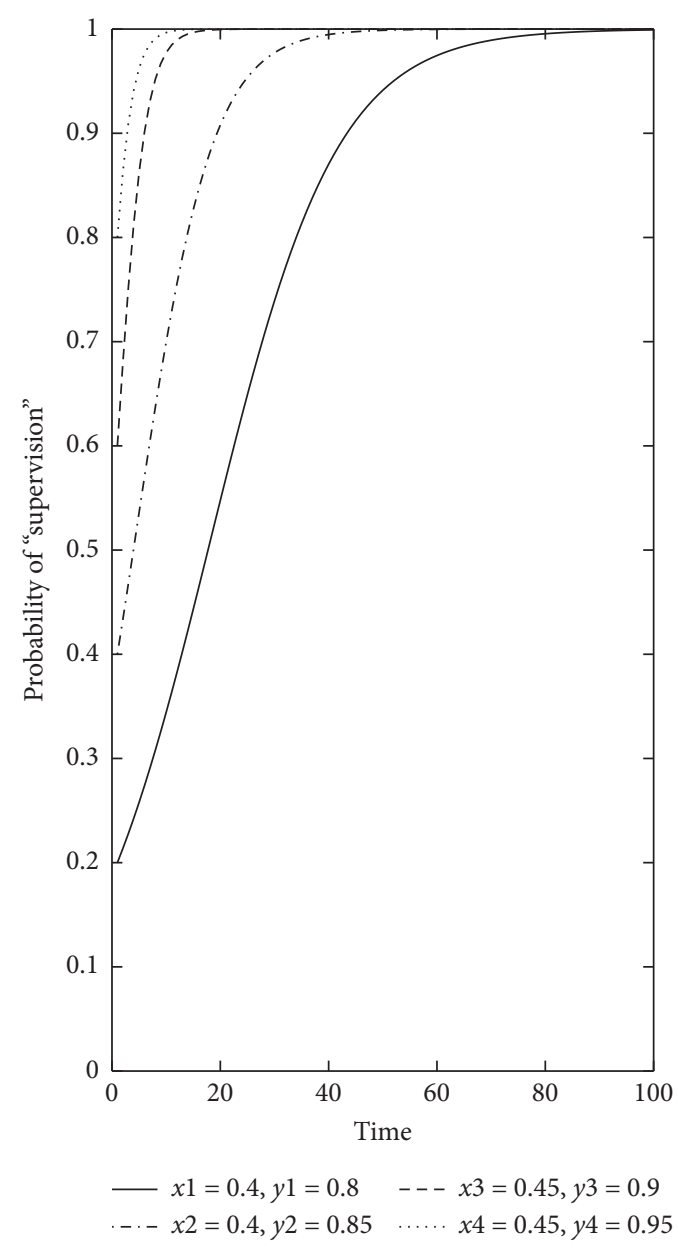

(b)

FIgURE 3: Evolutionary process of the government regulatory agency.

supervision is low, the evolutionary strategy of the power generator converges to 0 , i.e., the power generator will choose "compliance" strategy. When the probability of the compliance department choosing "strict inspection" is low, even if the probability of government supervision is high, the evolutionary strategy of the power generator converges to 1 , i.e., the power generator will choose "noncompliance" strategy.

Secondly, $y$ is fixed, and four groups of different values satisfying the conditions are selected for $x$ and $z$, respectively. The results are shown in Figure 2. It can be seen from the figure that the choices of the compliance department vary due to the different combinations of the strategies of the power generator and the government regulatory agency. Figure 2(a) meets the condition of $x>\left(C_{1}-C_{2} / z\left(T_{D}+L_{D}\right)\right.$ $\left.-R+E_{D}+F\right)$, while Figure 2(b) meets the condition of $x<\left(C_{1}-C_{2} / z\left(T_{D}+L_{D}\right)-R+E_{D}+F\right)$. It can be seen from the evolution results that when the probability of the power generator choosing "noncompliance" strategy is high, even if the probability of government supervision is low, the evolutionary strategy of the compliance department converges to 0 , i.e., the compliance department will choose "strict inspection" strategy. When the probability of the power generator choosing "noncompliance" strategy is low, even if the probability of government supervision is high, the evolutionary strategy of the compliance department converges to 1 , i.e., the compliance department will choose "lax inspection" strategy.

Lastly, $z$ is fixed, and four groups of different values satisfying the conditions are selected for $x$ and $y$, respectively. The results are shown in Figure 3. Figure 3(a) meets the condition of $y>\left(S-x G_{B} / x\left(T_{G}+T_{D}+G_{U}\right)\right)$, while Figure 3(b) meets the condition of $y<\left(S-x G_{B} / x\right.$ $\left.\left(T_{G}+T_{D}+G_{U}\right)\right)$. It can be seen from the evolution results that when the probability of the power generator choosing "noncompliance" strategy is high and the probability of the compliance department choosing "lax inspection" strategy is low, the evolutionary strategy of the government regulatory agency converges to 0 , i.e., the government regulatory agency will choose "nonsupervision" strategy. When the probability of the power generator choosing "noncompliance" strategy is low and the probability of the compliance department choosing "lax inspection" strategy is high, the evolutionary strategy of the government regulatory agency converges to 1 , i.e., the government regulatory agency will adopt "supervision" strategy. 


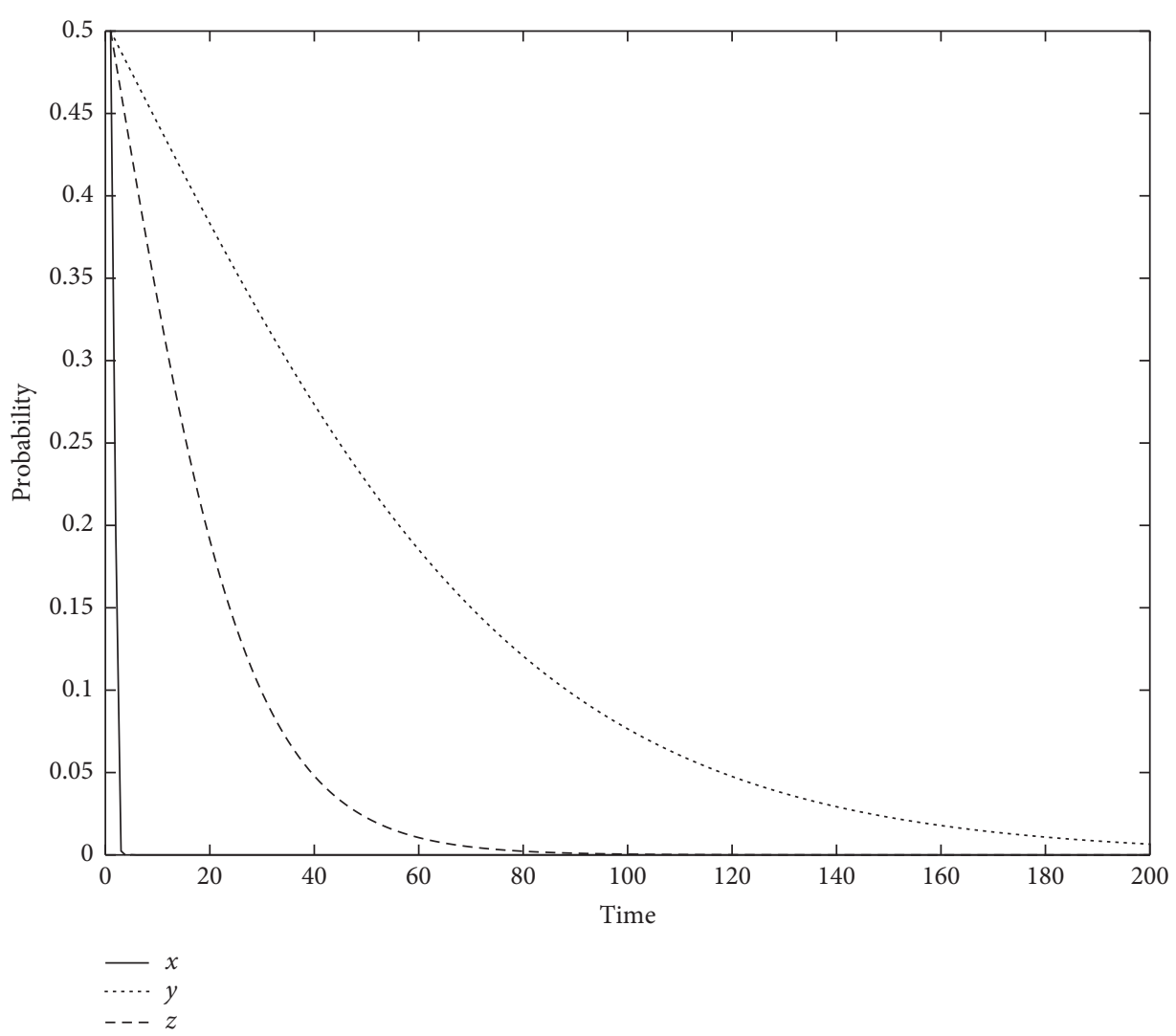

FIgURE 4: Evolutionary process of the entire system.

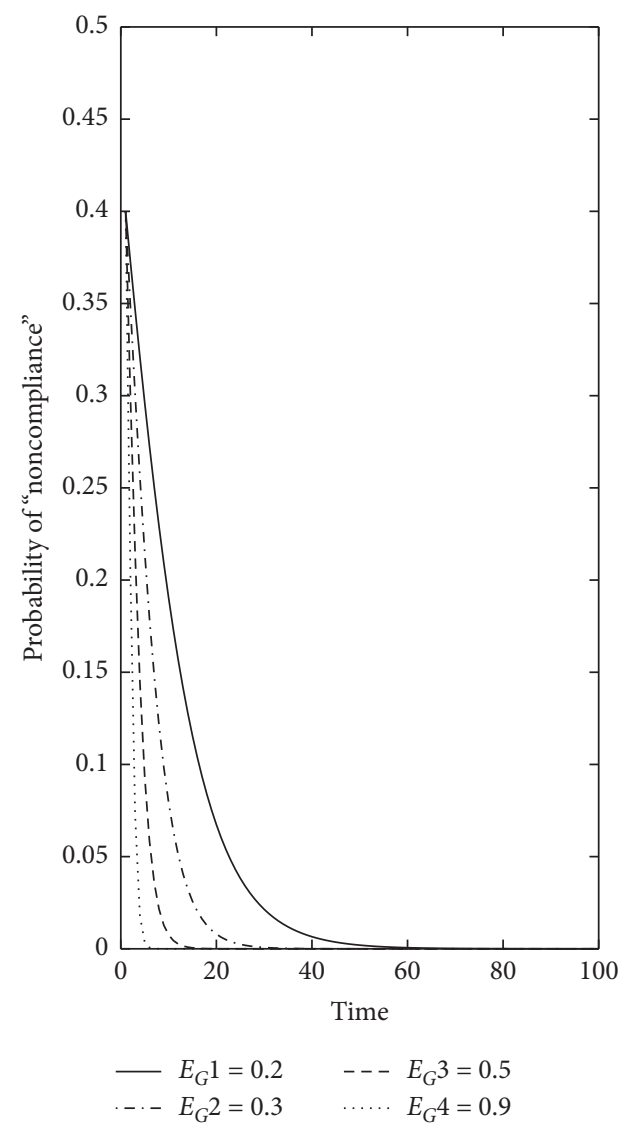

(a)

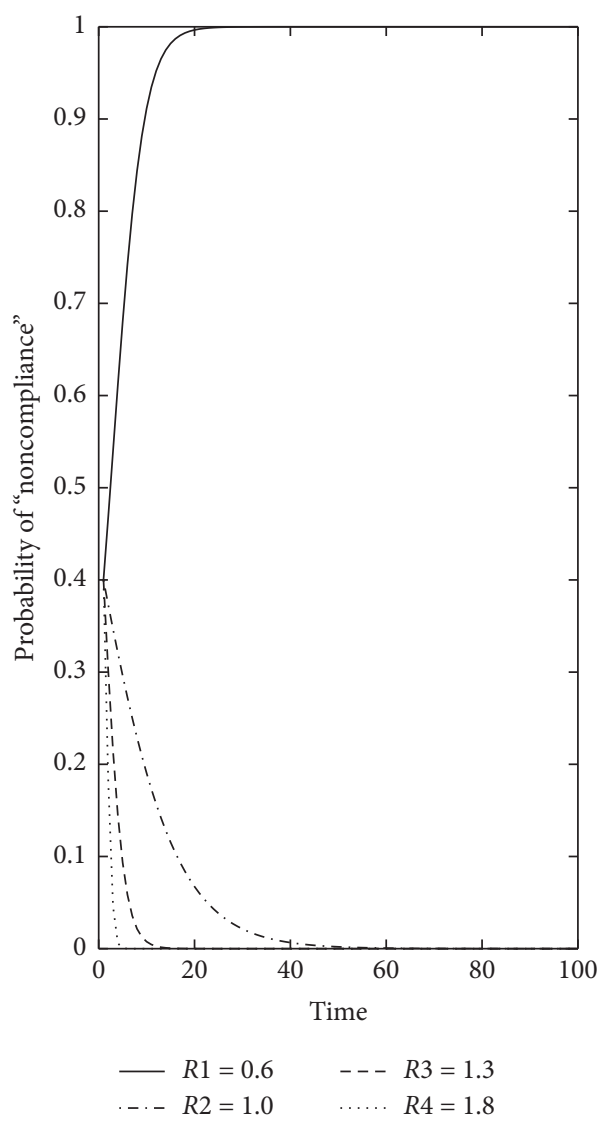

(b)

Figure 5: The effects of psychological costs and rent-seeking costs. 


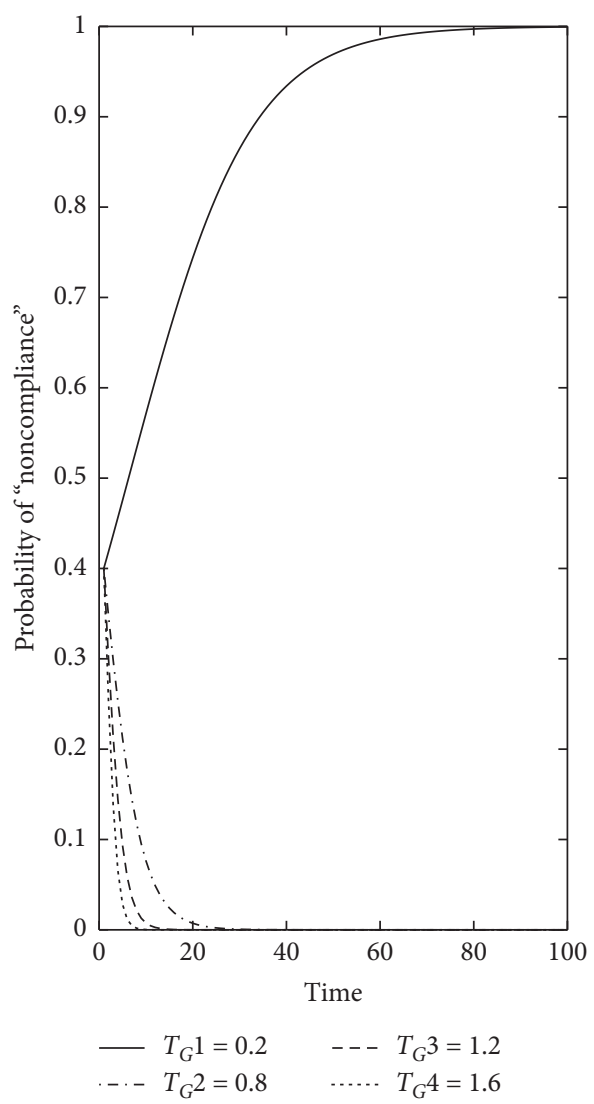

(a)

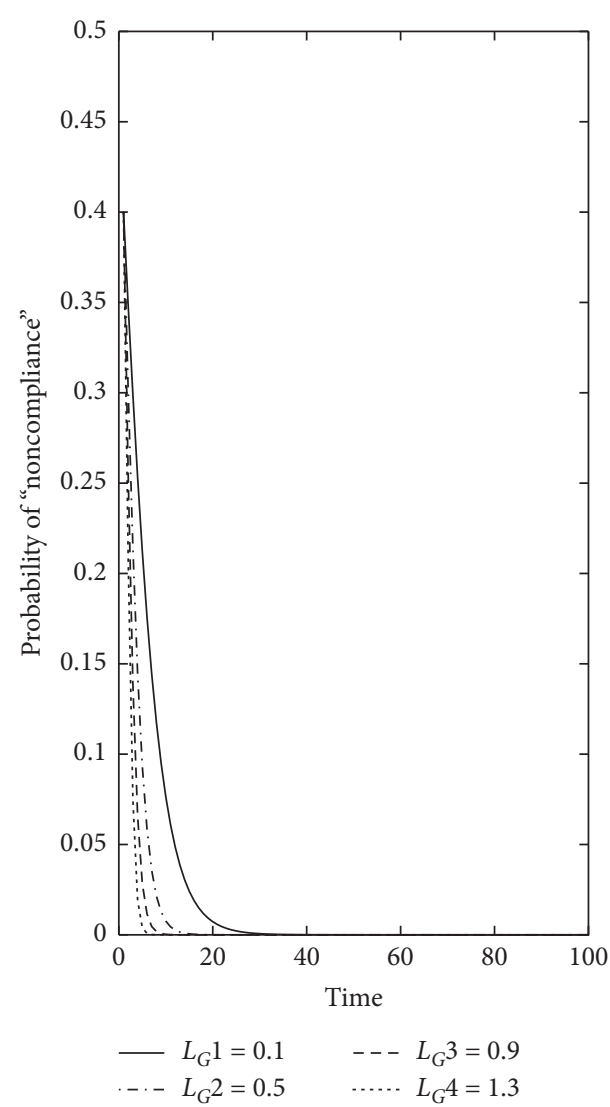

(b)

Figure 6: The effects of government fines $T_{G}$ and profit losses $L_{G}$.

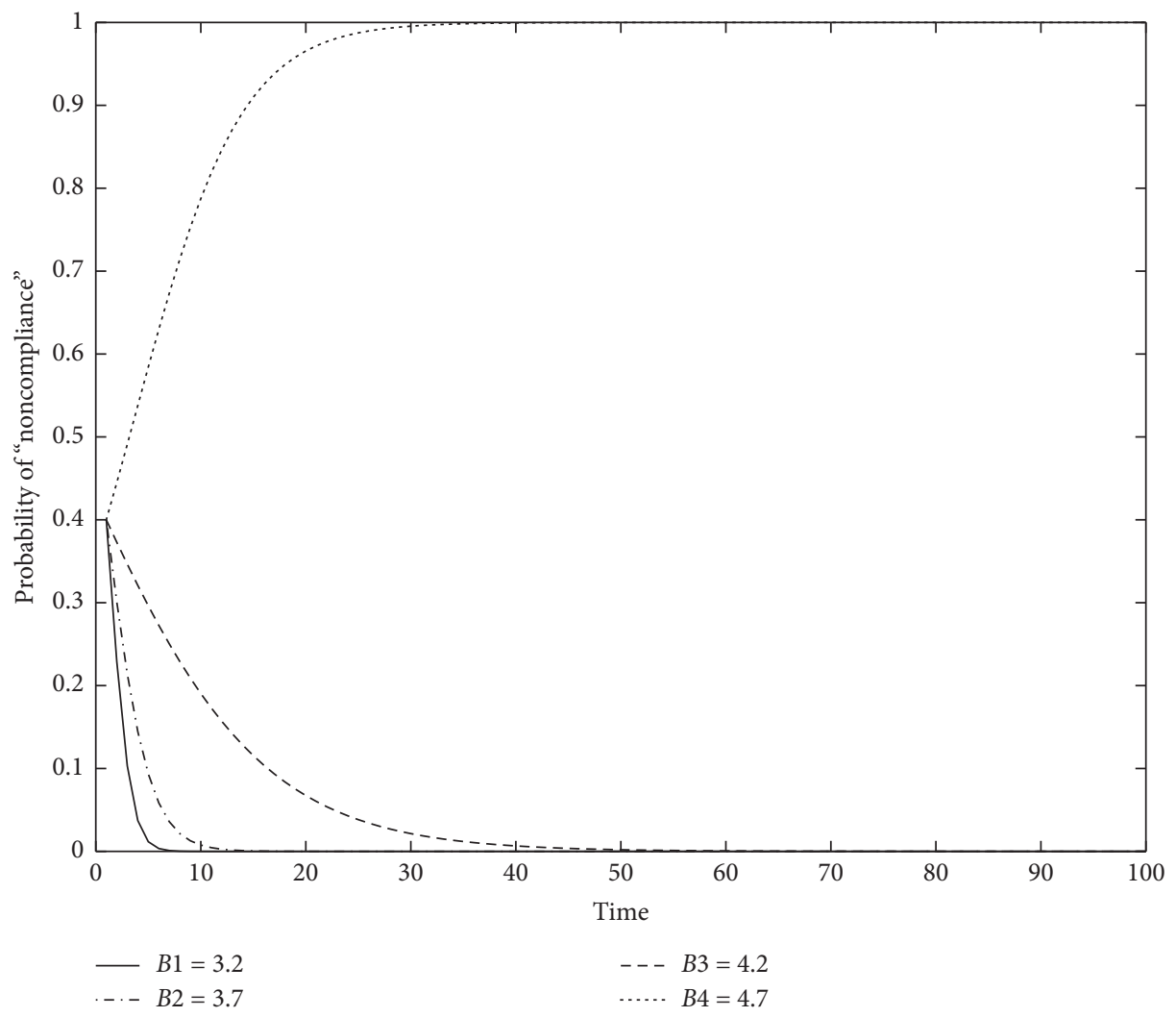

Figure 7: The effects of profits $B$. 


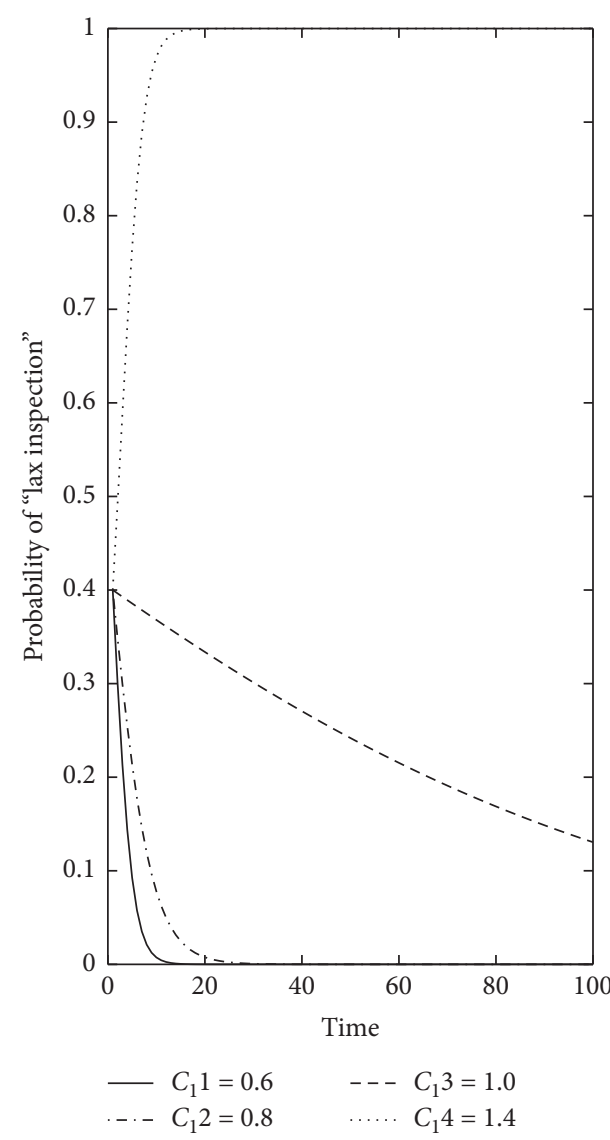

(a)

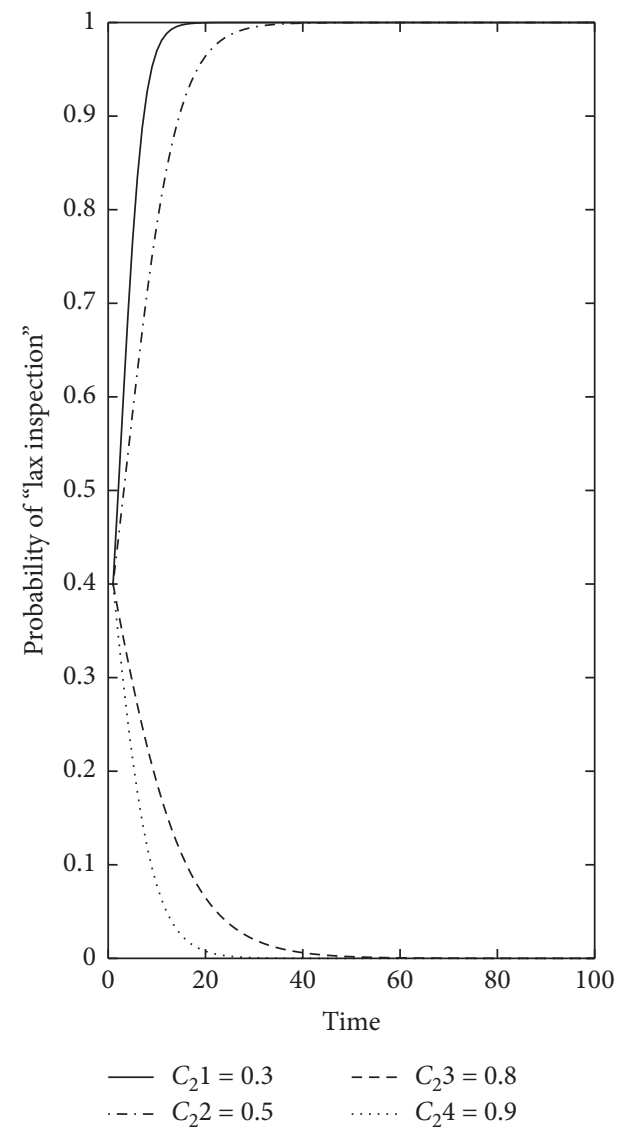

(b)

Figure 8: The effects of inspection costs.

To obtain the ESS of the entire system, let $x=y=z=0.5$, and keeping other parameters at their initial values, we can get Figure 4. As can be seen from Figure 4, the ESS of the power generator is "compliance," the ESS of the compliance department is "strict inspection," and the ESS of the government regulatory agency is "nonsupervision," i.e., the ideal point $\mathrm{A}(0,0,0)$ is realized.

4.2. Sensitivity Analysis of the Influencing Factors. To further explore the influence of different factors on the strategies of all players in this game, we conduct simulation analysis on the influencing factors of the three players, respectively, i.e., we change the initial values of the parameters which represent influencing factors to analyze the sensitivity of different strategies to different factors.

4.2.1. Sensitivity Analysis for the Power Generator. The strategies of the power generator are affected by psychological costs of violations, rent-seeking costs, government fines, profit losses caused by the disclosure of violations, profits from violations, and so on. The sensitivity analysis of parameters of these influencing factors is conducted as follows.
On the premise of keeping other parameters at the initial values, we change the psychological cost $E_{G}$ of the power generator. Apparently, it can be seen from Figure 5 that, as the psychological cost $E_{G}$ increases, the speed of the probability that the power generator choosing "noncompliance" strategy converges faster to 0 , i.e., the higher the psychological cost $E_{G}$, the higher the tendency of the power generator to choose "compliance" strategy. Similarly, on the premise of keeping the other parameters at the initial values, we change rent-seeking cost $R$ of the power generator. It can be seen from Figure 5 that, as the rent-seeking cost $R$ decreases, the speed of the probability that the power generator choosing "noncompliance" strategy converges slower to 0 , i.e., the lower the rent-seeking cost, the higher the tendency of the power generator to choose "noncompliance" strategy. When rent-seeking costs are reduced to a certain level, the ESS of the power generator will shift from "compliance" to "noncompliance."

If the power generator's violations are disclosed, the government will fine it. Therefore, the fine $T_{G}$ is one of the important factors influencing the strategy choice of the power generator. It can be seen from Figure 6 that, as the fine $T_{G}$ decreases, the speed of the probability that the power generator choosing "noncompliance" strategy converges slower to 0 . Moreover, when $T_{G}$ falls to a certain level, the 


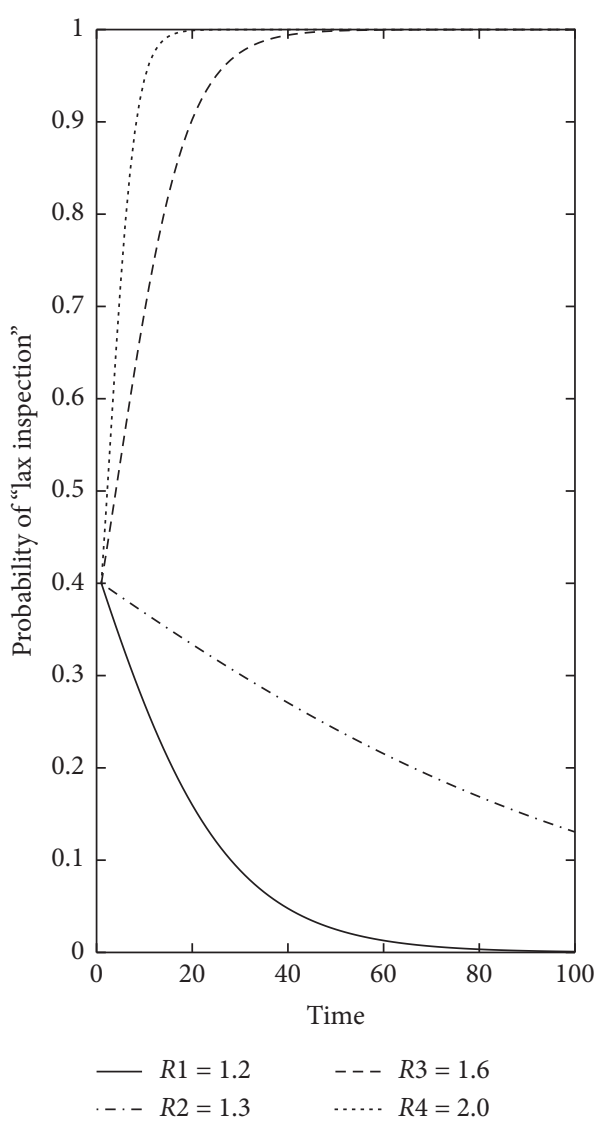

(a)

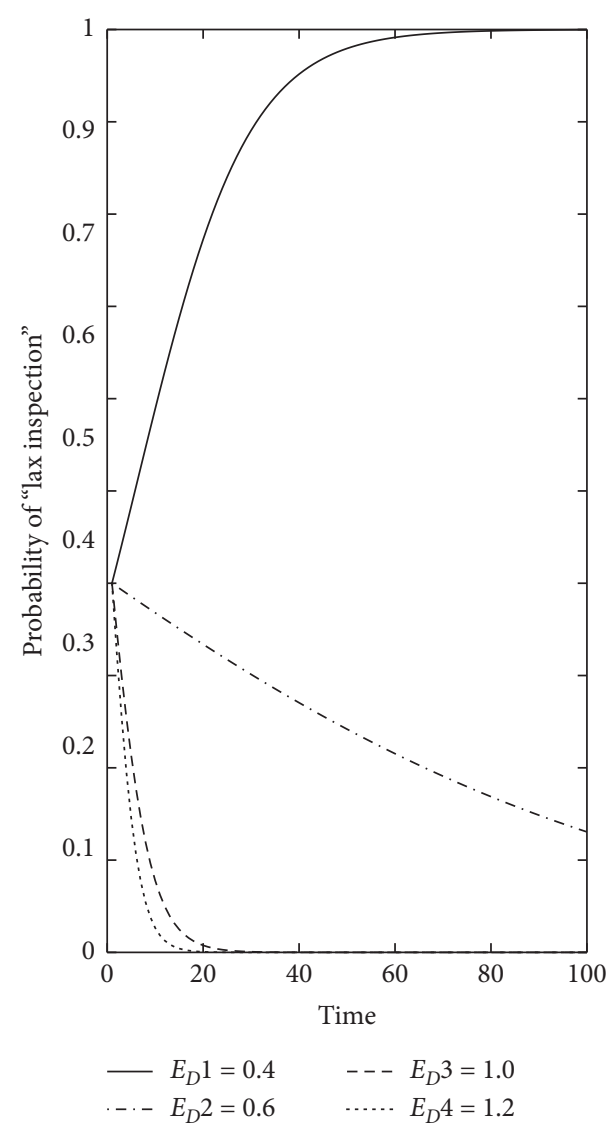

(b)

Figure 9: The effects of rent-seeking benefits and psychological costs.

ESS of the power generator will shift from "compliance" to "noncompliance." In addition, once the power generator's violations are exposed, its market competitiveness will also decline, and the loss will be $L_{G}$. As can be seen from Figure 6, as the profit loss $L_{G}$ increases, the speed of the probability that the power generator choosing "noncompliance" strategy converges faster to 0 . That is to say, the higher the profit loss, the higher the tendency of the power generator to choose "compliance" strategy.

In addition to the factors above, the increase in profits brought by violations is an extremely important factor that motivates the power generator to violate regulations. It is the incentive of profits that motivate the power generator to adopt "noncompliance" strategy. It can be seen from Figure 7 that, as profits $B$ increase, the speed of the probability that the power generator choosing "noncompliance" strategy converges slower to 0 . When $B$ increases to a certain level, the ESS of the power generator will shift from "compliance" to "noncompliance."

4.2.2. Sensitivity Analysis for the Compliance Department of the Trading Centre. The strategies of the compliance department of the trading centre are affected by factors such as inspection costs, rent-seeking benefits, psychological costs, reputation, and government fines. The sensitivity analysis of parameters of these influencing factors is conducted as follows.
The strict inspection cost of the compliance department is $C_{1}$. It can be seen from Figure 8 that, as the strict inspection cost increases, the speed of the probability that the compliance department choosing "lax inspection" strategy converges slower to 0 . Furthermore, when the strict inspection cost increases to a certain level, the ESS of the compliance department will shift from "strict inspection" to "lax inspection." The lax inspection cost is $C_{2}$. It can be seen from Figure 8 that, as the lax inspection cost decreases, the speed of the probability that the compliance department choosing "lax inspection" strategy converges slower to 0 . When the lax inspection cost decreases to a certain level, the ESS of the compliance department will shift from "strict inspection" to "lax inspection."

The rent-seeking benefit is the most important factor that motivates the compliance department to collude with the power generator. It can be seen from Figure 9 that, as the rent-seeking benefit increases, the ESS of the compliance department will shift from "strict inspection" to "lax inspection." In addition, the compliance department has to bear psychological cost when colluding with the power generator. It can be seen from Figure 9 that, as the psychological cost decreases, the ESS of the compliance department will shift from "strict inspection" to "lax inspection."

The strict inspection of the compliance department can bring it good reputation which carries benefits. Therefore, 


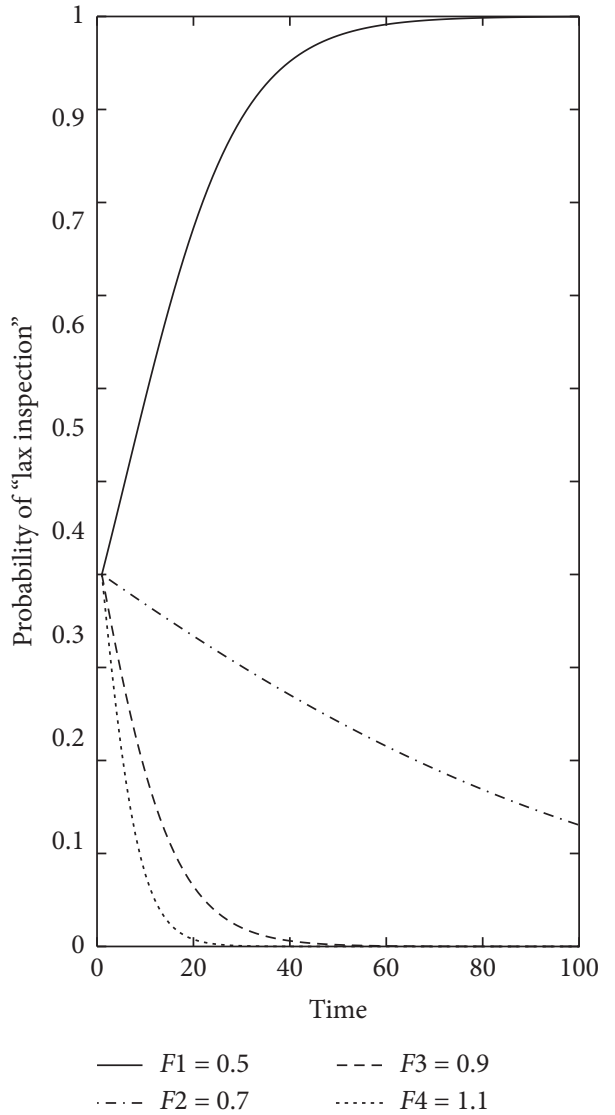

(a)

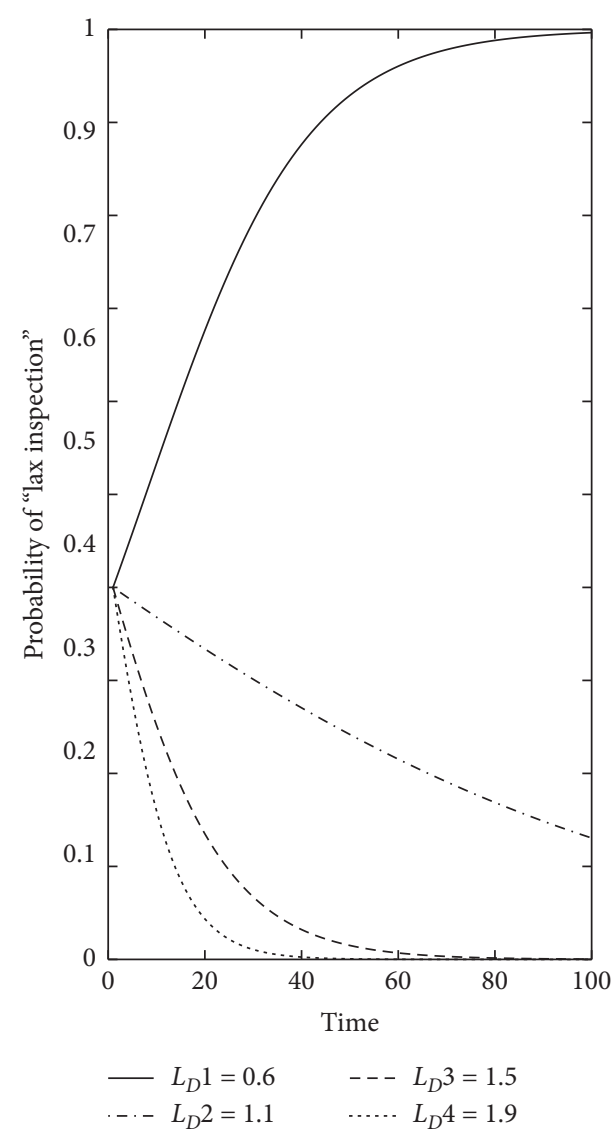

(b)

FIgURE 10: The effects of reputation.

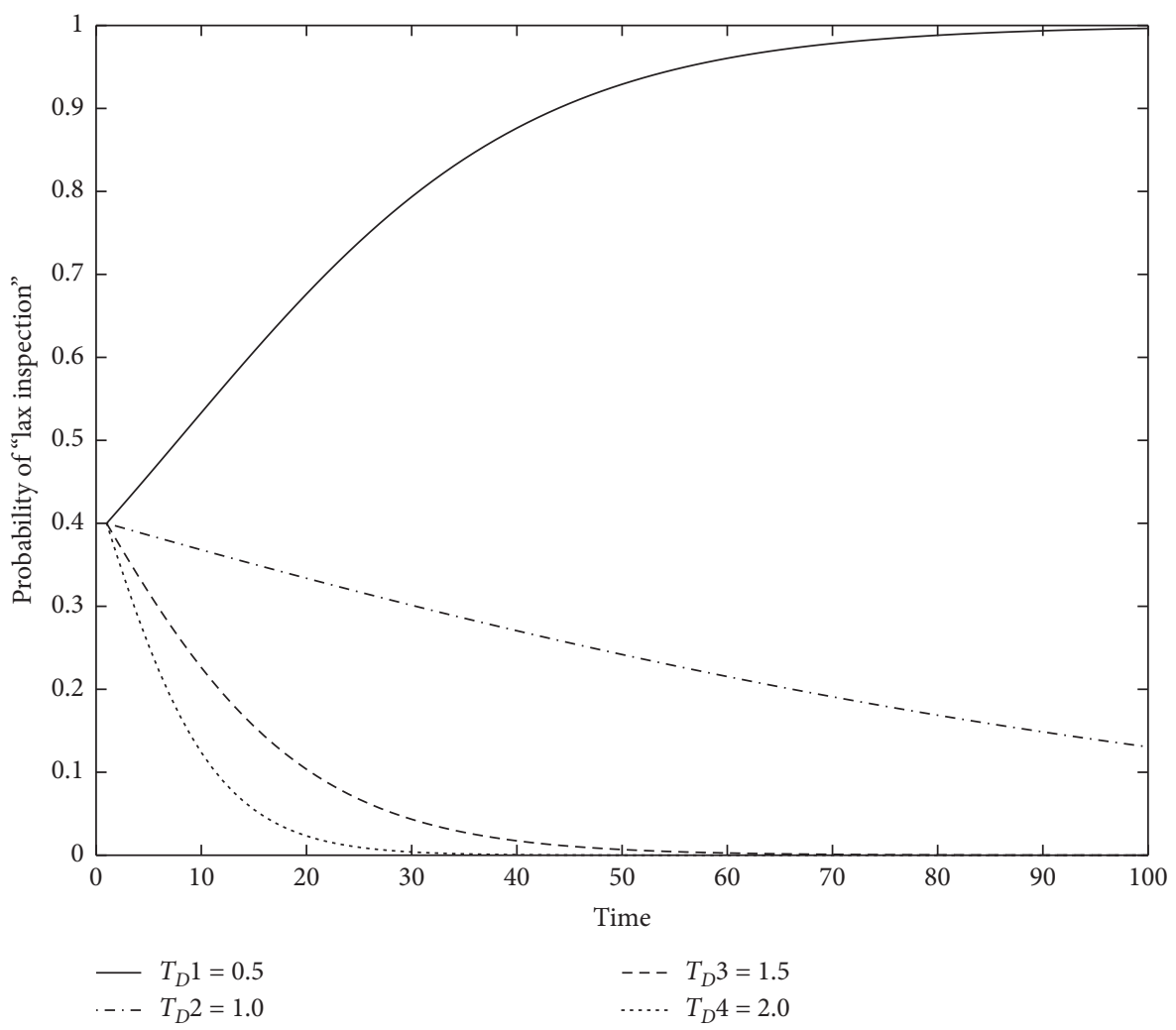

Figure 11: The effects of government fines. 


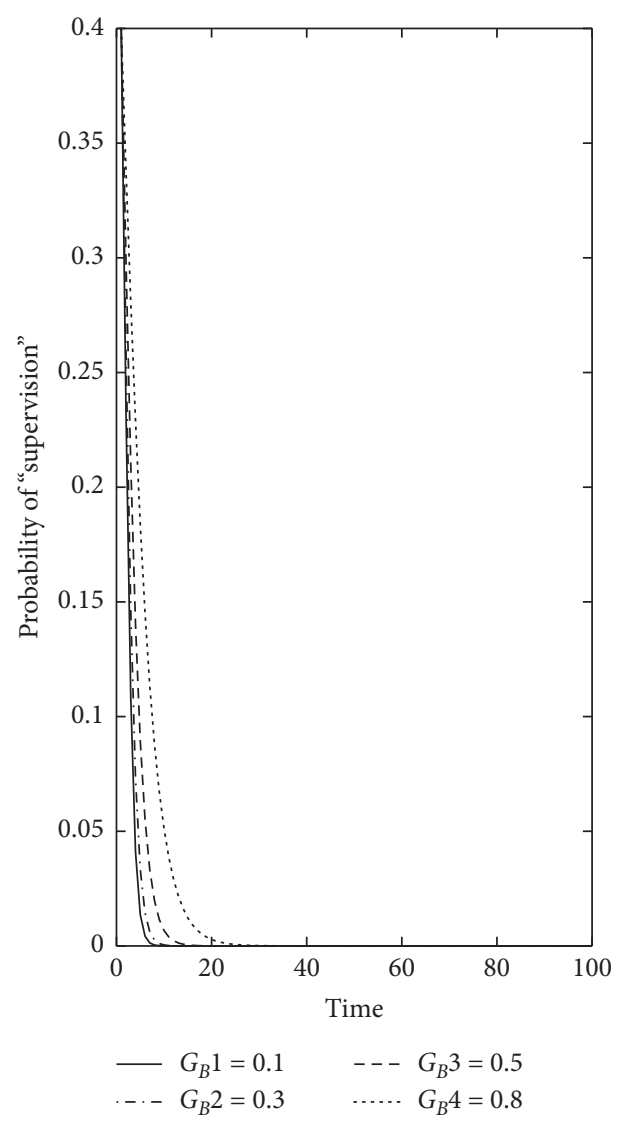

(a)

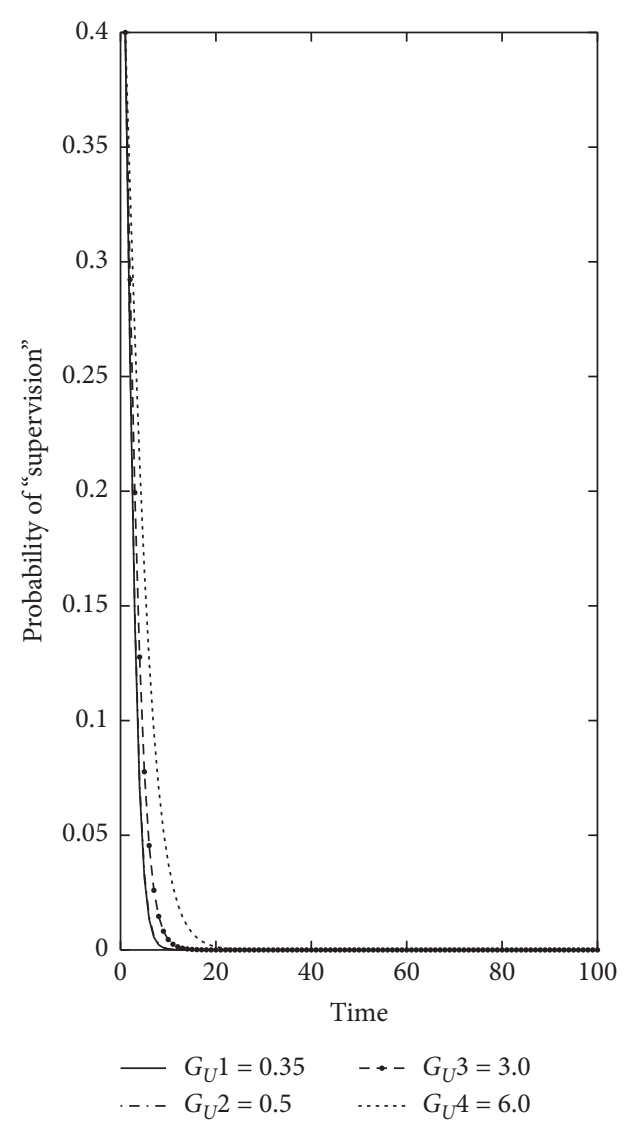

(b)

Figure 12: The effects of reputation.

the compliance department will weigh the reputation gains when making strategy choices. It can be seen from Figure 10 that, as the reputation benefit brought by strict inspection decreases, the ESS of the compliance department will shift from "strict inspection" to "lax inspection." However, once the compliance department adopts "lax inspection" strategy while the violation is found by the government regulatory agency, its reputation would decline, which will bring negative effects. It can be seen from Figure 10 that, as the loss of reputation decreases, the ESS of the compliance department gradually shifts from "strict inspection" to "lax inspection."

If the government regulatory agency finds that the compliance department and the power generator collude with each other, it will punish both of them. The government fine will affect the compliance department's strategy choices. It can be seen from Figure 11 that, as the fine decreases, the ESS of the compliance department gradually shifts from "strict inspection" to "lax inspection."

4.2.3. Sensitivity Analysis for the Government Regulatory Agency. The strategy choice of the government regulatory agency is influenced by reputation, fine revenue, supervision cost, etc. The sensitivity analysis of parameters of these influencing factors is conducted as follows.
The behavior of the government regulatory agency will affect its reputation. If the government adopts "supervision" strategy and discovers violations in the electricity market, its reputation is enhanced. On the contrary, if the government adopts "nonsupervision" strategy and fails to find the violations in the market, its reputation will be damaged. It can be seen from Figure 12 that, as the positive impact brought by the reputation enhancement increases, the speed of the probability that the government regulatory agency choosing "nonsupervision" strategy converges slower to 0 . That is to say, the higher the reputation gains, the higher the tendency of the government regulatory agency to choose "supervision" strategy. Similarly, as the negative impact brought by the reputation decline increases, the speed of the probability that the government regulatory agency choosing "nonsupervision" strategy converges slower to 0 . That is to say, the higher the reputation loss, the higher the tendency of the government regulatory agency to choose "supervision" strategy.

The government will punish the participants violating regulations in the electricity market and hold the compliance department accountable for its inspection of the market. It can be seen from Figure 13 that, as the fines increase, the speed of the probability that the government regulatory agency choosing "nonsupervision" strategy converges slower to 0 . That is to say, the higher the fines, the higher the 


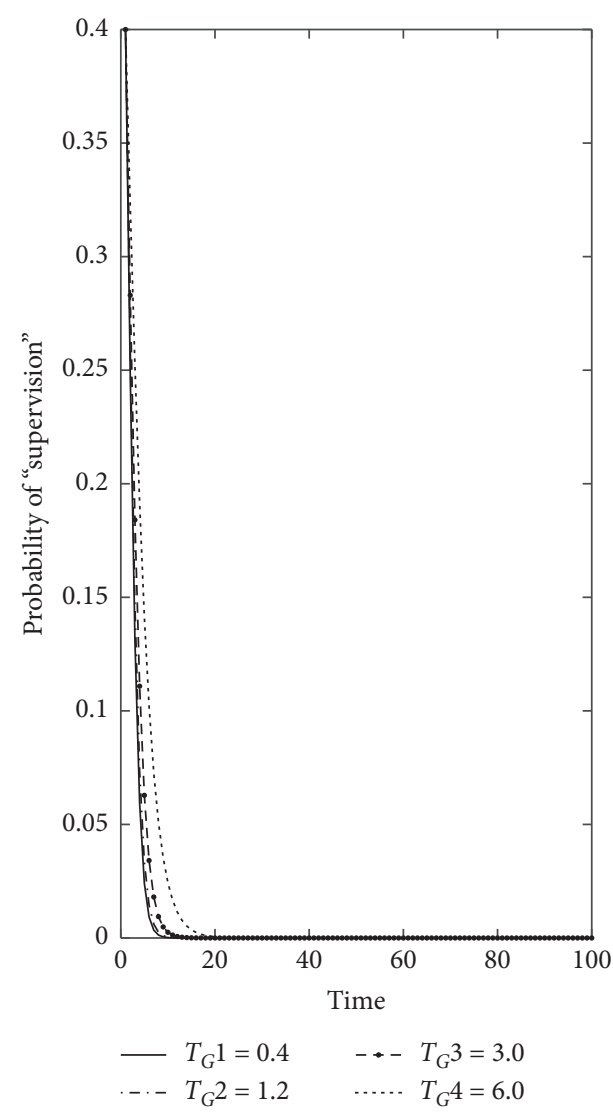

(a)

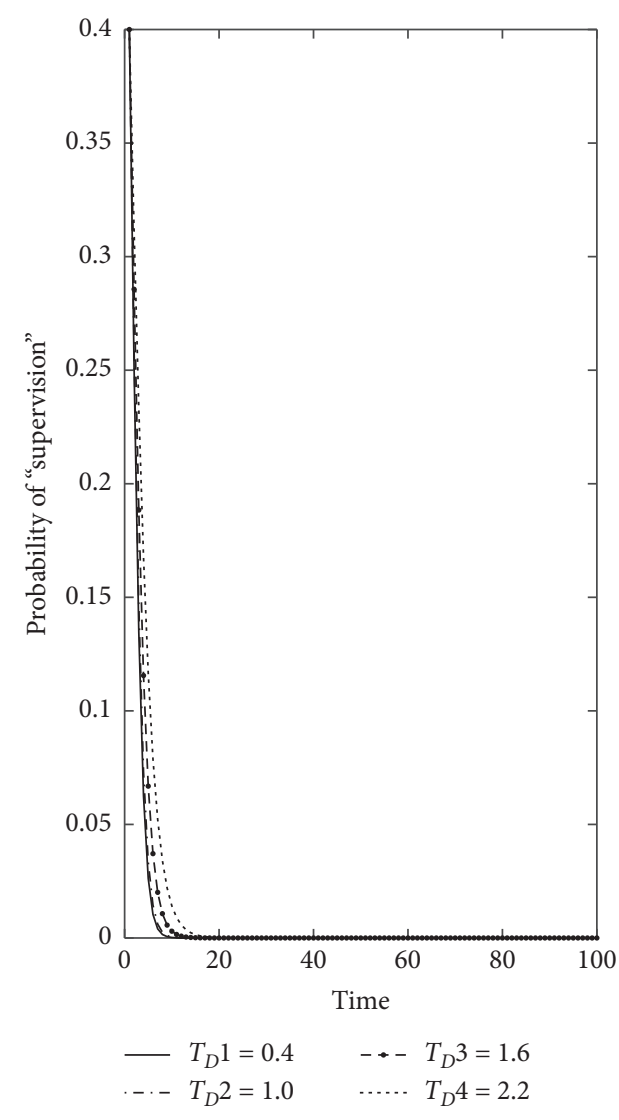

(b)

FIgURE 13: The effects of fine revenue.

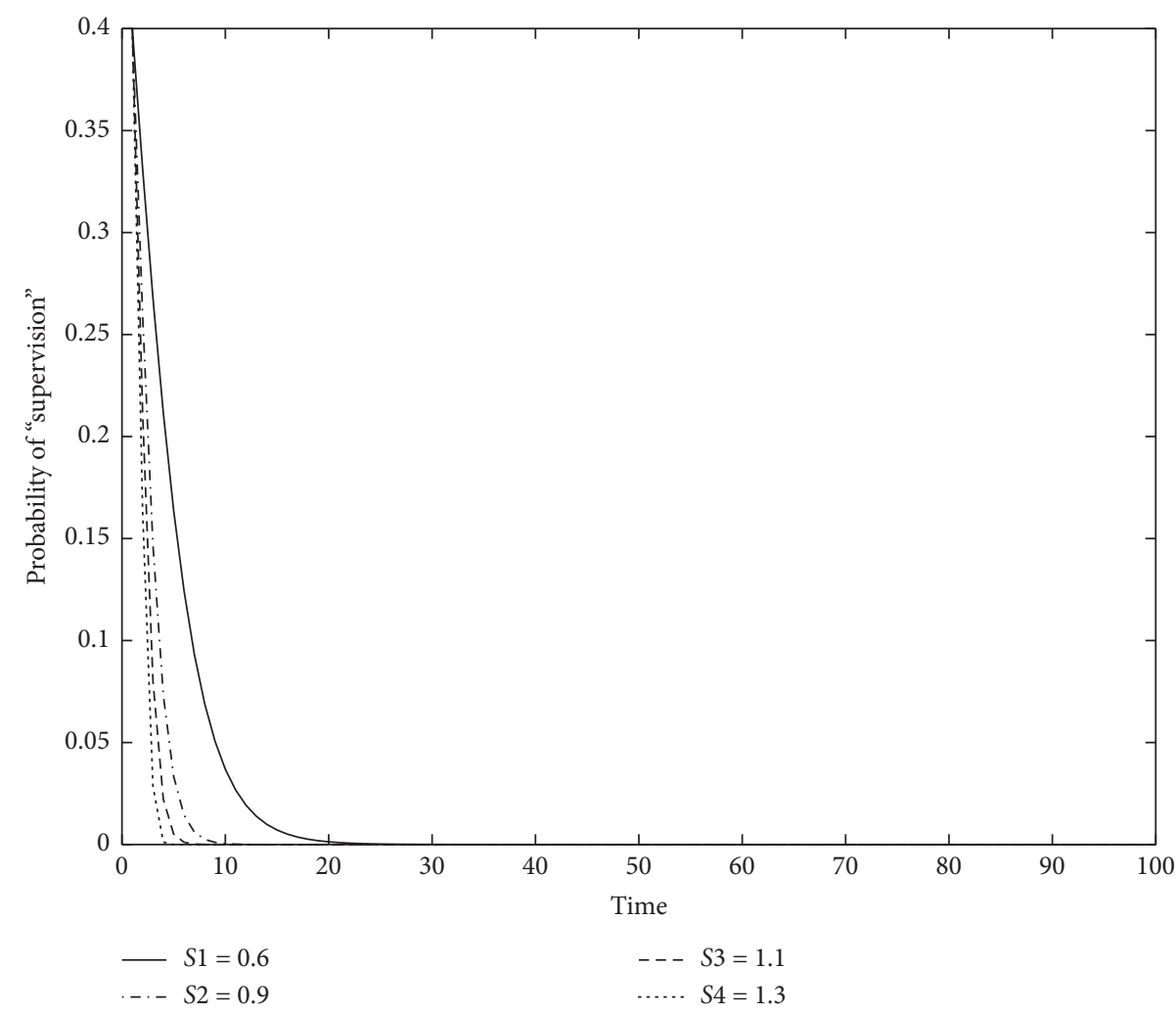

FIgURE 14: The effects of supervision costs. 
tendency of the government regulatory agency choosing "supervision" strategy.

The supervision cost is also an important factor that affects the strategic choice of government regulators. It can be seen from Figure 14 that, as the supervision cost decreases, the speed of the probability that the government regulatory agency choosing "nonsupervision" strategy converges slower to 0 . That is to say, the lower the supervision cost, the higher the tendency of the government regulatory agency to choose "supervision" strategy.

\section{Conclusion and Policy Recommendations}

This paper constructs an evolutionary game among the power generator, the compliance department of the trading centre, and the government regulatory agency, exploring the evolutionary process of the strategy choices of the three players and influencing factors. The results show that the strategy choices of both the power generator and the government regulator are mainly affected by the inspection of the compliance department of the trading centre. Under certain conditions, the trading centre will fully exert its inspection duty so that there is no need for government supervision. Under this circumstance, the power generator will consciously follow market rules, and the efficiency of compliance management in the power industry is maximized with minimum cost. Moreover, according to the results of sensitivity analysis, the costs and benefits are most important factors affecting the strategies of market participants. Therefore, the electricity market needs to establish a credit management system as well as a reward and punishment mechanism. Meanwhile, certain measures should be taken to stimulate market competition and encourage market participants to consciously follow market rules. More importantly, the electricity market shall reduce the inspection cost of the compliance department of the trading centre and establish an appropriate incentive mechanism to promote the compliance department of the trading centre to strictly inspect market participants.

\section{Data Availability}

The data used to support the findings of this study are available from the corresponding author upon request.

\section{Conflicts of Interest}

The authors declare no conflicts of interest.

\section{Acknowledgments}

This work was supported by the National Natural Science Foundation of China (Grant nos. 71874149 and 71934001) and the National Social Science Fund of China (Grant no. 20ZDA084).

\section{References}

[1] M.-L. Song and L.-B. Cui, "Economic evaluation of Chinese electricity price marketization based on dynamic computational general equilibrium model," Computers \& Industrial Engineering, vol. 101, pp. 614-628, 2016.

[2] B. C. Xie, J. Xu, and M. Pollitt, "What effect has the 2015 power market reform had on power prices in China? Evidence from Guangdong and Zhejiang," Faculty of Economics, University of Cambridge, Cambridge, UK, Cambridge Working Papers in Economics, 2020.

[3] M. A. Ansari, S. Haider, and N. A. Khan, "Does trade openness affects global carbon dioxide emissions," Management of Environmental Quality: An International Journal, vol. 31, no. 1, pp. 32-53, 2020.

[4] W. Wang, "The path of China electric power regulatory system reform under the new round of electricity reform," Journal of the Party School of the Central Committee of the C.P.C.vol. 20, no. 5, pp. 108-112, 2016.

[5] M. Song, R. Fisher, and Y. Kwoh, "Technological challenges of green innovation and sustainable resource management with large scale data," Technological Forecasting and Social Change, vol. 144, pp. 361-368, 2019.

[6] M. Liu and F. F. Wu, "Risk management in a competitive electricity market," International Journal of Electrical Power \& Energy Systems, vol. 29, no. 9, pp. 690-697, 2007.

[7] A. K. Singh and S. K. Parida, "Congestion management with distributed generation and its impact on electricity market," International Journal of Electrical Power \& Energy Systems, vol. 48, pp. 39-47, 2013.

[8] T. Tang and J. Yang, "The compliance analysis on transaction risk of electricity market based on the release of retail side," in Proceedings of the 2016 2nd International Conference on Advances in Energy, Environment and Chemical Engineering (AEECE 2016), vol. 89, pp. 36-39, Singapore, July 2016.

[9] M. K. Alashery and W. Qiao, "Risk management for optimal wind power bidding in an electricity market: a comparative study," in Proceedings of the 2018 North American Power Symposium (NAPS), Fargo, ND, USA, September 2018.

[10] D. Srivastava and S. K. Srivastava, "Congestion management approaches in deregulated electricity market: a comprehensive review of outcomes, challenges and opportunities," in Proceedings of the 2018 International Conference on Power Energy, Environment and Intelligent Control, PEEIC 2018, pp. 315-319, Greater Noida, India, April 2018.

[11] M. Hupez, Z. De Grève, and F. Vallée, "Cooperative demandside management scenario for the low-voltage network in liberalised electricity markets," IET Generation, Transmission \& Distribution, vol. 12, no. 22, pp. 5990-5999, 2018.

[12] J. Gao and Z. Sheng, "Elementary groping for evolutionary game theory and its application in electricity market," $\mathrm{Au}$ tomation of Electric Power Systems, vol. 27, no. 18, pp. 18-21, 2003.

[13] D. Menniti, A. Pinnarelli, and N. Sorrentino, "Simulation of producers behaviour in the electricity market by evolutionary games," Electric Power Systems Research, vol. 78, no. 3, pp. 475-483, 2008.

[14] X. Huang and Z. Wang, "Analysis of bidding strategies of generation companies by evolutionary game theory," Modern Electric Power, vol. 3, pp. 62-65, 2009.

[15] J. Wang, Z. Zhou, and A. Botterud, "An evolutionary game approach to analyzing bidding strategies in electricity markets with elastic demand," Energy, vol. 36, no. 5, pp. 3459-3467, 2011.

[16] D. Fang, C. Zhao, and Q. Yu, "Government regulation of renewable energy generation and transmission in China's electricity market," Renewable and Sustainable Energy Reviews, vol. 93, pp. 775-793, 2018. 
[17] L. Cheng and T. Yu, "Nash equilibrium-based asymptotic stability analysis of multi-group Asymmetric evolutionary games in typical scenario of electricity market," IEEE Access, vol. 6, pp. 32064-32086, 2018.

[18] C. Zhu, R. Fan, and J. Lin, "The impact of renewable portfolio standard on retail electricity market: a system dynamics model of tripartite evolutionary game," Energy Policy, vol. 136, Article ID 111072, 2020.

[19] E. Zhao, H. Wang, H. Lin et al., "Simulation analysis of power spot market based on evolutionary game," Journal of Physics: Conference Series, vol. 1624, no. 2, Article ID 022069, 2020.

[20] K. Ritzberger and J. W. Weibull, "Evolutionary selection in normal-form games," Econometrica, vol. 63, no. 6, pp. 1371-1399, 1995.

[21] D. Friedman, "Evolutionary games in economics," Econometrica, vol. 59, no. 3, pp. 637-666, 1991. 